\title{
Presynaptic GABA Receptors Mediate Temporal Contrast Enhancement in Drosophila Olfactory Sensory Neurons and Modulate Odor-Driven Behavioral Kinetics
}

\author{
(D)Davide Raccuglia, ${ }^{1}$ - Li Yan McCurdy, ${ }^{1,2}$ Mahmut Demir, ${ }^{3}$ Srinivas Gorur-Shandilya, ${ }^{2}$ Michael Kunst, ${ }^{1}$ \\ (1)Thierry Emonet, ${ }^{3,4}$ and Michael N. Nitabach ${ }^{1,5,6}$
}

\section{DOI:http://dx.doi.org/10.1523/ENEURO.0080-16.2016}

${ }^{1}$ Department of Cellular and Molecular Physiology, Yale University School of Medicine, New Haven, Connecticut 06520, ${ }^{2}$ Interdepartmental Neuroscience Program, Yale University, New Haven, Connecticut 06520, ${ }^{3}$ Department of Molecular, Cellular and Developmental Biology, Yale University, New Haven, Connecticut 06520, ${ }^{4}$ Department of Physics, Yale University, New Haven, Connecticut 06520, ${ }^{5}$ Department of Genetics, Yale University School of Medicine, New Haven, Connecticut 06520, ${ }^{6}$ Program in Cellular Neuroscience, Neurodegeneration and Repair, Yale University School of Medicine, New Haven, Connecticut 06520

\section{Visual Abstract}

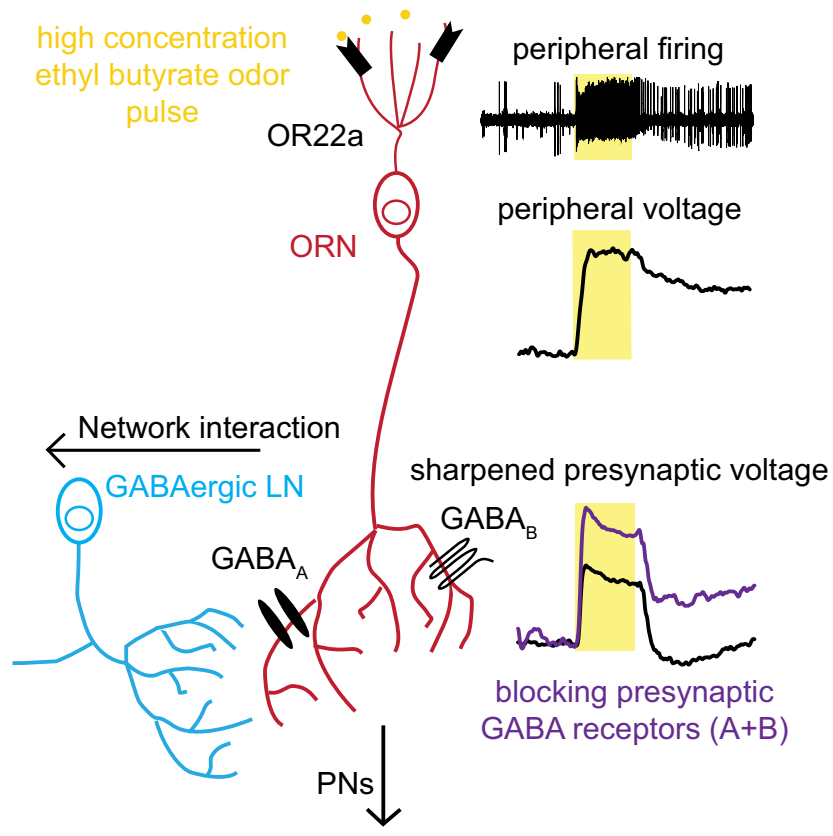

temporally contrast enhanced behavioral response

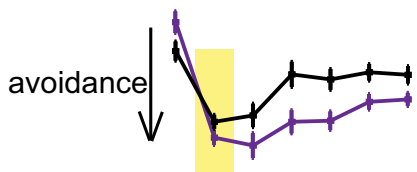

Contrast enhancement mediated by lateral inhibition within the nervous system enhances the detection of salient features of visual and auditory stimuli, such as spatial and temporal edges. However, it remains unclear how mechanisms for temporal contrast enhancement in the olfactory system can enhance the detection of odor plume edges during navigation. To address this question, we delivered to Drosophila melanogaster flies pulses of high odor intensity that induce sustained peripheral responses in olfactory sensory neurons (OSNs). We use optical electrophysiology to directly measure electrical responses in presynaptic terminals and demonstrate that sustained peripheral responses are temporally sharpened by the combined activity of two types of inhibitory GABA receptors to generate contrast-enhanced voltage responses in central OSN axon terminals. Furthermore, we show how these GABA receptors modulate the time course of innate behavioral responses after odor pulse termination, demonstrating an important role for temporal contrast enhancement in odor-guided navigation.

\section{Introduction}

Incoming sensory stimuli trigger network activity involving mutually connected excitatory and inhibitory neurons.

\footnotetext{
Received April 13, 2016; accepted July 21, 2016; First published July 25, 2016. The authors declare no competing financial interests.

Author contributions: D.R., L.Y.M., M.D., S.G.-S., M.K., T.E., and M.N.N. designed research; D.R., L.Y.M., and M.D. performed research; S.G.-S., M.K., and T.E. contributed unpublished reagents/analytic tools; D.R., L.Y.M., M.D., and S.G.-S. analyzed data; D.R. and M.N.N. wrote the paper.

Work in the laboratory of M.N.N. was supported in part by the National Institute of Neurological Disorders and Stroke, the National Institutes of Health
} (NIH; Grants R01-NS-055035, R01-NS-056443, and R01-NS-091070); the 


\section{Significance Statement}

Contrast enhancement of visual, auditory, and olfactory information shapes the spatial and temporal perception of our environment. The cellular mechanisms that mediate temporal contrast enhancement of olfactory information and their impact on behavior are not fully understood. We therefore use optical electrophysiology to investigate how presynaptic GABA receptors in olfactory sensory neurons of Drosophila melanogaster shape olfactory information and how this affects odor-driven behavioral kinetics. We find that the combined activity of two types of inhibitory GABA receptors mediates temporal contrast enhancement and modulates behavioral kinetics after an odor pulse, demonstrating the importance of this mechanism for odor-guided navigation.

Integration of these opposing signals is essential for robust environmental perception (Anderson et al., 2000; Wehr and Zador, 2003; Poo and Isaacson, 2009). In the mammalian retina, for example, lateral inhibition mediated by GABAergic interneurons enhances contrast sensitivity, and, thus, the ability to discriminate spatial differences in light intensities underlying object and motion detection (Kuffler, 1953; Buldyrev and Taylor, 2013). Animals also rely on the sense of smell to navigate their environments (Wallace et al., 2002). Odor plumes emitted by food sources and distributed by air currents guide sniffing and are temporally encoded by olfactory sensory neurons (OSNs) enabling odor-directed navigation (Mylne and Mason, 1991; Cury and Uchida, 2010; Shusterman et al., 2011; Celani et al., 2014). How inhibitory GABA receptors modulate neuronal activity to mediate temporal contrast enhancement and how it affects odor-driven behavioral kinetics is not fully understood.

In the vertebrate olfactory bulb (OB), GABAergic local interneurons (LNs) provide presynaptic inhibition to OSNs (Lledo et al., 2004). Presynaptic inhibition of OSNs mediates gain control, maintenance, and refinement of odorspecific neuronal activity within and between glomeruli (Urban, 2002; McGann et al., 2005; Pírez and Wachowiak, 2008). While it is clear that presynaptic inhibition maintains the encoding of odor identity over a wide range of odor intensities, it is unknown whether presynaptic inhibition also mediates temporal contrast enhancement. The anatomies of the mammalian and Drosophila olfactory systems are remarkably similar (Ache and Young, 2005; Kaupp, 2010). In Drosophila, the dendrites and cell bodies

National Institute of General Medical Sciences (NIGMS), NIH (Grant R01GM098931); and the Kavli Institute for Neuroscience. L.Y.M. was supported by a Gruber Science Fellowship and NIGMS, NIH (Grant T32GM007223).

Acknowledgments: We thank Ronald L. Davis for providing UAS-rdl-RNAi (GABA $\left._{A}-\mathrm{RNAi}\right)$ flies. We also thank Glenn Turner for technical advice. In addition, we thank the Yale Center for Innovation Engineering and Design for technical assistance with the construction of the behavioral arena.

Correspondence should be addressed to Davide Raccuglia, present address: Institute of Neurophysiology, Charité-Universitätsmedizin Berlin, Berlin, Germany. E-mail: davide.raccuglia@charite.de.

DOI:http://dx.doi.org/10.1523/ENEURO.0080-16.2016

Copyright (C) 2016 Raccuglia et al.

This is an open-access article distributed under the terms of the Creative Commons Attribution 4.0 International, which permits unrestricted use, distribution and reproduction in any medium provided that the original work is properly attributed. of OSNs reside in sensilla on the antennae and maxillary palps (Vosshall et al., 1999; Vosshall et al., 2000; Couto et al., 2005). Presynaptic OSN axon terminals expressing the same olfactory receptor protein converge onto glomeruli in the antennal lobe (AL), a neuropil analogous to the mammalian OB (Vosshall et al., 1999; Vosshall et al., 2000; Couto et al., 2005). Presynaptic inhibition by Drosophila LNs is known to mediate gain control (Olsen and Wilson, 2008; Root et al., 2008) and the refinement of odor-evoked spatial patterns of activation of glomeruli (Silbering and Galizia, 2007). More recently, postsynaptic electrical recordings have been used to show that presynaptic inhibition enables broadband transmission of rapidly fluctuating odor pulses and sharpens responses to brief transient stimuli (Nagel et al., 2015). Due to technical restraints, it was thus far not possible to directly visualize the effects of presynaptic inhibition on electrical responses in presynaptic terminals. Moreover, it remains unclear how presynaptic GABA receptors affect postpulse neuronal activity directly in the OSN terminals and how this activity can affect odor-guided navigation with respect to temporal contrast enhancement.

We therefore used voltage imaging to directly compare electrical activity in the peripheral somata of OSN with their presynaptic terminals. Interestingly, we found that these odor stimuli induce sustained postpulse responses in the peripheral somata and dendrites of OSNs. The activity of presynaptic ionotropic $\mathrm{GABA}_{A}$ and metabotropic $G_{A B A}$ inhibitory receptors generates contrastenhanced voltage responses in OSN terminals, and also accelerates behavioral responses to the termination of an intense odor pulse. We demonstrate how presynaptic GABA receptors modulate neuronal activity to mediate gain control and temporal contrast enhancement, which together improve behavioral performance and could enhance plume-guided navigation.

\section{Materials and Methods}

\section{Experimental preparation}

Fly stocks were raised on standard cornmeal food at $25^{\circ} \mathrm{C}$ and $60 \%$ humidity under a $12 \mathrm{~h} \mathrm{light/dark} \mathrm{regime.}$ Wild-type Drosophila strains Canton-S and w1118 were used in this study. The following transgenic lines were used: UAS-ArcLight (Cao et al., 2013); UAS-GCaMP6f (Chen et al., 2013); UAS-pdf-RNAi (Ni et al., 2009); UAS$G A B A_{A}-R N A i$ (8-10G, used for all physiological experi- 
ments and 2-7E2; Liu et al., 2009); UAS-GABA $A_{B}-R N A i$ (Root et al., 2008); UAS-Dcr-2 (Dietzl et al., 2007); and Or22a-GAL4, Or42b-GAL4, OR42a-GAL4 (Vosshall et al., 2000).

For recordings of olfactory responses, female flies between 3 and $7 \mathrm{~d}$ posteclosion were used. For imaging and electrophysiological recordings of the antennae, standard procedures were used (de Bruyne et al., 2001). For immobilization, a fly was pushed all the way into a truncated $200 \mu \mathrm{l}$ pipette tip. One of the exposed antennae was then stabilized between a tapered glass micropipette and double-sided tape attached to a cover glass. For imaging of the central brain, the preparation was modified after the method of Fiala and Spall (2003). Briefly, flies were anesthetized and, using two-component adhesive epoxy, immobilized on sticky tape attached to a hole-punched plastic coverslip. To further immobilize the head, an insect pin was gently pushed against the head and attached to the plastic coverslip using Paraplast wax. After the cuticle was exposed, a thin layer of epoxy was used to seal gaps between the head and the sticky tape. After letting the epoxy harden for 30-60 min, the cuticle above the head, air sacks, and glands were removed under insect saline containing the following (in $\mathrm{mM}$ ): $\mathrm{NaCl} 103, \mathrm{KCl} 5, \mathrm{CaCl}_{2} 2$, $\mathrm{MgCl}_{2}$ 4, $\mathrm{NaHCO}_{3}$ 26, $\mathrm{NaH}_{2} \mathrm{PO}_{4}$ 1, TES 5, trehalose 10, and glucose 10, pH 7.4. Picrotoxin (PTX; Abcam) and CGP54626 (CGP; Tocris Bioscience) were dissolved as 20 $\mathrm{mm}$ stock solution in DMSO, and then diluted in insect saline and used as 200 and $100 \mu \mathrm{M}$.

\section{Imaging and electrophysiology}

Imaging was performed on a Zeiss Axio Examiner upright microscope using a Plan Apochromat $40 \times$, numerical aperture (NA) 1.0, water-immersion objective (Zeiss, Germany) for imaging of the central brain, and a LMPlanFI $50 \times$, NA 0.5, air-objective (Olympus) for imaging of the antenna. Using a Colibri LED system (Zeiss), ArcLight and GCamp were excited at $470 \mathrm{~nm}$. LED power was adjusted for each recording individually to make sure that fluorescent image was not saturated. The objective C-mount image was projected onto the $80 \times 80$ pixel chip of a NeuroCCD-SM camera controlled by NeuroPlex software (RedShirtlmaging). For image demagnification, we used an Optem C-to-C mount 25-70-54 0.38× (LINOS, Qioptiq). Voltage imaging was performed at a frame rate of 125 $\mathrm{Hz}$, and calcium imaging was performed at a frame rate of $40 \mathrm{~Hz}$. Optical traces were obtained as spatial averages of intensity of all pixels within the region of interest, with signals processed as reported elsewhere (Jin et al., 2012; Cao et al., 2013) with double-exponential fitting to compensate for rapid and slow photobleaching followed by eight rounds of box-car smoothing.

Single sensillum recordings (SSRs) were performed as described previously (de Bruyne et al., 2001). Electrical signals were amplified using an Iso-DAM amplifier (World Precision Instruments), bandpass filtered $(300 \mathrm{~Hz}$ to 2 $\mathrm{kHz}$ ), digitized at $10 \mathrm{kHz}$ (NI-USB6221 Digital Acquisition Board, National Instruments), and acquired using data acquisition software that is freely available at https:// github.com/sg-s/kontroller. Spikes were identified and sorted using a spike-sorting toolbox available at https:// github.com/sg-s/spikesort.

\section{Odor delivery}

Odorants were delivered using a custom gas-phase dilution olfactometer. Compressed medical air (Airgas) was split into three airstreams, and the flow rate of each airstream was regulated with mass flow controllers (Alicat Scientific). Two airstreams were combined to create the specific odor dilutions. One of those two airstreams passed over a $20 \mathrm{ml}$ glass vial containing $5 \mathrm{ml}$ of pure ethyl butyrate (Eb; 99\%; Sigma-Aldrich). This airstream was combined with the other airstream, which passed through an empty vial. By changing the ratios of flow rates between the two airstreams, various gas-phase dilutions of the odorant were obtained. A computer-controlled three-way solenoid valve (NResearch Inc.) delivered the odorized airstream either to a waste outlet or to the fly via a glass delivery tube $\sim 2 \mathrm{~cm}$ away from the fly. For all imaging experiments, the total air volume directed at the fly was $600 \mathrm{ml} / \mathrm{min}$. The odor concentration was monitored using a photo ionization detector (200B, Aurora Scientific), which was placed either directly adjacent to the fly $(2-4 \mathrm{~mm})$ or at the opening of the odor delivery tube. For all purely electrophysiological experiments (Fig. 1), we used two mass flow controllers to dilute odorants in a secondary airstream with a flow rate of $200 \mathrm{ml} / \mathrm{min}$. This secondary airstream was diverted into a main airstream (2000 $\mathrm{ml} / \mathrm{min}$ ) using computer-controlled solenoid valves (Lee Co.). The photoionization detector (PID) was used to make sure that dilutions using this odor delivery system were comparable to the dilutions used during imaging experiments.

\section{Innate avoidance and attraction assay}

For behavioral experiments, we used a custom-built arena, comprising a circular acrylic base $(10 \mathrm{~cm}$ diameter) and a Petri dish lid that enclosed the arena. Four openings for odor ports were drilled into the outer layer of the circular base (each $90^{\circ}$ ). The height inside the arena was $1.5 \mathrm{~mm}$, providing sufficient height for the flies to walk but not to fly. The arena was illuminated from the bottom by an LED light box (Huion). Videos were collected at 30 frames per second (fps) using a high speed digital camera (Casio EX-FC150).

Experiments were conducted in a dark room maintained at $50 \%$ humidity. To increase locomotor activity, experiments were conducted at $30^{\circ} \mathrm{C}$ (Zaninovich et al., 2013; Clark et al., 2014). The 3- to 7-d-old flies were food deprived for 12-24 $\mathrm{h}$ in vials with wet Kimwipes. Before each experiment, 30-50 male and female flies were allowed to acclimatize inside the arena for $5 \mathrm{~min}$. Odor pulses were subsequently presented in increasing concentrations with interpulse intervals of $1 \mathrm{~min}$. The odor port used was randomized for each experiment from among four available in the arena. For $10 \mathrm{~s}$ pulse experiments, each concentration was tested twice. For $1 \mathrm{~s}$ pulse experiments, each concentration was tested once. After each experiment, flies were discarded, and the arena and odor tube were aired for $10 \mathrm{~min}$ to clear residual odorant before performing the next experiment. 
A

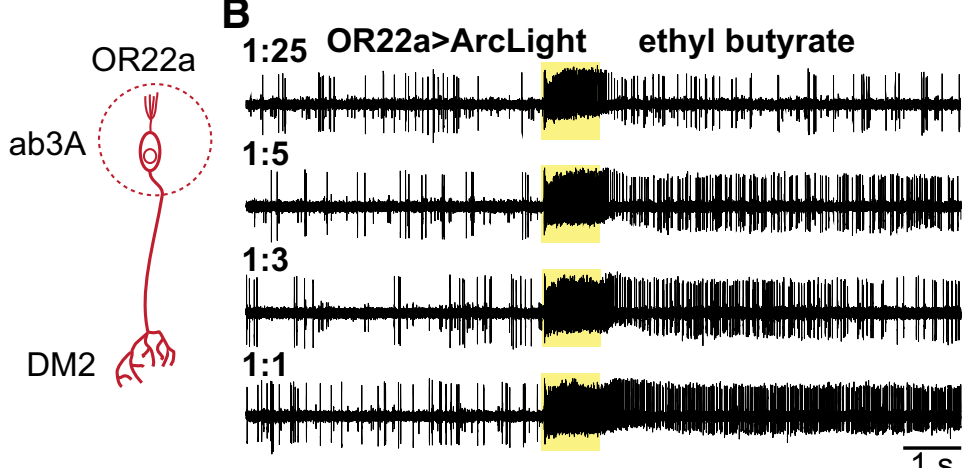

C

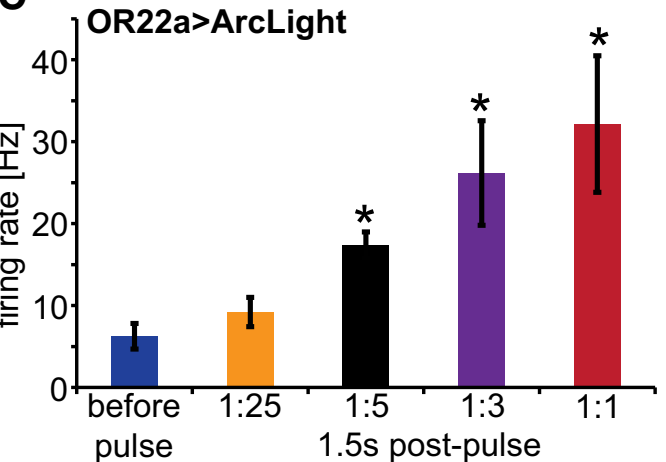

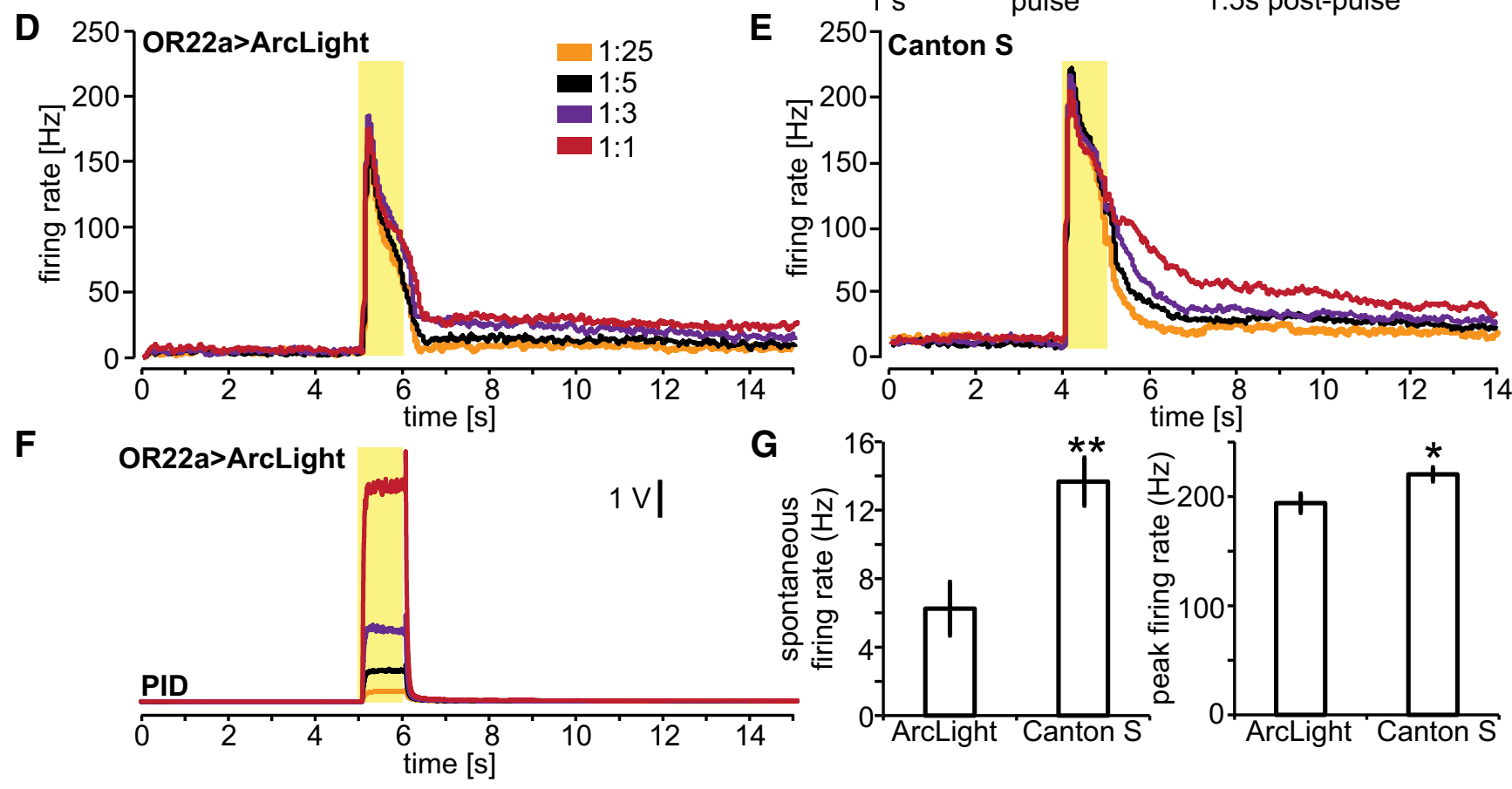

H

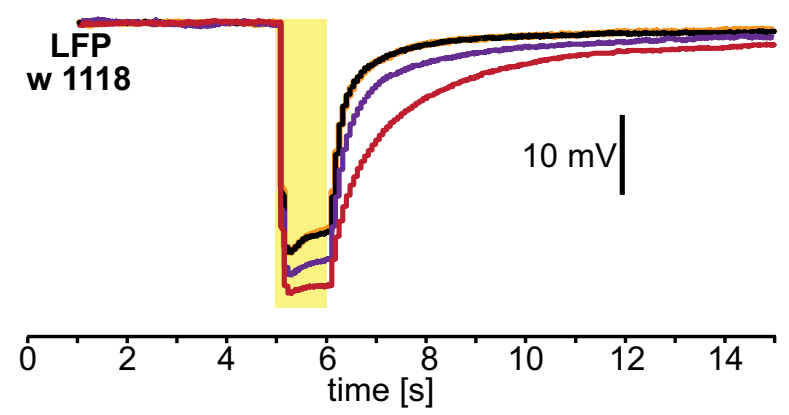

Figure 1. Increasing odor concentrations induces sustained peripheral OSN responses. $\boldsymbol{A}$, An OSN depicting the dendrites and cell body in the antenna and the presynaptic axon terminals in the antennal lobe. The circle indicates focus on odor-elicited activity in the dendrites and cell body. B, Extracellular SSRs of action potentials in an ab3 sensillum, which contains OR22a-expressing OSNs. One second pulses of Eb of the indicated gas-phase dilutions were delivered during the indicated interval (yellow box). Recordings are representative of those obtained from four flies and 10 sensilla per concentration. $\boldsymbol{C}$, Comparison between the spontaneous and postpulse firing rate at $1.5 \mathrm{~s}$ after odor pulse offset shows sustained firing for odor intensities of $\geq 1: 5$. Mean $\pm \mathrm{SEM} ; n=4$. Statistical analysis: one-way ANOVA for repeated measurements with Dunn's post hoc test (spontaneous firing as control); $* p<0.05$. $\boldsymbol{D}$, Mean firing rates ( $n=4$ flies) of a neuron recorded in ab3 sensilla of ArcLight-expressing flies. $\boldsymbol{E}$, Mean firing rates ( $n=4$ flies) of a neuron recorded in ab3 sensilla of Canton $\mathbf{S}$ flies. $\boldsymbol{F}$, Representative odor signals measured at the outlet of the odor delivery system using a PID. G, OR22a-OSNs expressing ArcLight display reduced spontaneous and odor-induced peak firing rates compared with wild-type OR22a-OSNs (Canton S). Data from $\boldsymbol{D}$ and $\boldsymbol{E}$ were averaged across concentrations. Statistical analysis: unpaired $t$ test, $* p$ $<0.05 ; * * p<0.01$. $\boldsymbol{H}$, Mean LFP $(n=3)$ of ab3 sensilla in w1118 flies showing sustained neuronal activity. 
The detection and tracking of the flies were performed using a modified open-source MATLAB code (http:// studentdavestutorials. weebly.com/kalman-filter-withmatlab-code.html). For $10 \mathrm{~s}$ pulse experiments, the location of each fly and its distance from the odor port was calculated every 15 frames $(0.5 \mathrm{~s})$ for a total of $35 \mathrm{~s}$, and the average distance from odor port over time was plotted. For $1 \mathrm{~s}$ pulse experiments, flies were individually tracked at $30 \mathrm{fps}$ over a period of $4.5 \mathrm{~s}$, and the relative distance moved with respect to the initial position of each fly during odor onset $(\Delta d)$ was calculated. We defined $\Delta d_{t}$ as the difference in distance from the odor port between odor onset and time $t\left(\Delta d_{t}=d_{0}-d_{t}\right)$, such that positive $\Delta d_{t}$ values reflect movement toward the odor port (i.e, attraction) and negative values reflect movement away (i.e., avoidance).

\section{Results}

\section{Sustained peripheral OSN responses measured by classic and optical electrophysiology}

As previously reported, increasing odor concentrations tend to prolong peripheral firing in OSNs (Martelli et al., 2013). To investigate whether this prolonged firing is subject to central processes of contrast enhancement, we first determined odor concentrations that induce sustained peripheral odor responses. We chose the fruittypical odor Eb, which strongly activates a large number of olfactory receptors (Hallem and Carlson, 2006). Because Eb elicits the strongest response in OR22aexpressing OSNs (de Bruyne et al., 2001), we measured the peripheral responses of these neurons to Eb pulses (Figs. 1, 2). We used both extracellular SSRs (Fig. 1) and high-speed imaging of the ArcLight genetically encoded fluorescent voltage indicator expressed in OR22aexpressing OSNs (Fig. 2). The SSR of OR22a-expressing OSNs in the ab3 sensillum indicates that Eb pulses at gas-phase dilutions of $1: 5$ and higher odor concentrations elicit sustained post-pulse action potential firing trains (Fig. 1A-D, for statistics see Table 1). To determine the intensity and time course of odor delivery at the different gas-phase dilutions, we directly measured odor intensity with a PID positioned at the odor outlet (Fig. $1 F$ ) as in the study by Martelli et al. (2013). To exclude the possibility that the expression of ArcLight alters OSN excitability to induce these sustained responses, we performed SSR on ab3 sensilla of wild-type Canton S flies, revealing that they also exhibit sustained responses after the termination of Eb pulses (Fig. 1E). However, compared with Canton S, the expression of ArcLight leads to reduced spontaneous and odor-induced peak firing rate in OR22a-expressing OSNs (Fig. 1G), indicating that ArcLight reduces neuronal excitability. This is most likely because ArcLight adds capacitance to the neurons, as shown for pigment dispersing factor (PDF)-expressing neurons (Cao et al., 2013). As ArcLight does not increase excitability, the observed sustained neuronal activity cannot be due to the expression of ArcLight. We also measured the local field potential (LFP) for another strain of flies (LFP of w1118; Fig. $1 H$ ), which also indicates sustained neuronal activity.
Whether the sustained peripheral activity is due to postpulse lingering odor or intracellular cascades triggered at high concentrations remains to be investigated. We further chose to focus on whether the observed sustained activity is subject to central processes of contrast enhancement modulating odor-driven behavioral kinetics.

To test whether ArcLight-mediated optical electrophysiology can be used reliably to detect sustained peripheral electrical responses, we performed simultaneous SSRs from an ab3 sensillum and voltage imaging of the OR22aexpressing OSNs across the entire antenna (Fig. 2B-E). While SSRs can capture the firing rate of a single type of neuron, voltage imaging of the entire antenna averages the neuronal activity of all OR22a-expressing OSNs (Fig. $2 A)$. To determine the time course of the odor stimulus experienced by the fly, we positioned the PID next to the fly (as is the case for all subsequent experiments). At a $1: 25$ dilution of $\mathrm{Eb}$, the odor was barely detectable by the PID at the position of the fly (Fig. 2B). The dynamics of neuronal activity reported by ArcLight fluorescence (Fig. $2 C)$ accurately recapitulates instantaneous firing frequency measured by SSR (Fig. $2 B$ ) and is in accordance with known features of OSN activation, including adaptation and poststimulus inhibition (Hallem and Carlson, 2006; Nagel and Wilson, 2011; Martelli et al., 2013). At the higher concentration (1:5 dilution), the odor pulse was readily detectable by the PID, and the sustained postpulse firing that lasts for several seconds becomes evident (Fig. 2D). Interestingly, at this high odor intensity the peripheral firing rate (Fig. 2D) and peripheral ArcLight fluorescence (Fig. 2E) are not identical. First, while sensory adaptation is pronounced in the firing rate, it is not present in the ArcLight fluorescence. Second, the firing rate shows a steep decline after offset and remains at $\sim 20-40 \%$ of the offset firing rate (Fig. 2D). Arclight fluorescence shows no steep decline after offset and remains at $\sim 80-90 \%$ of the offset fluorescence signal (Fig. 2E). A possible explanation for these differences is that the ArcLight fluorescence also reflects the receptor potential, while the firing rate does not. In addition, it is also possible that, due to the dynamic range of ArcLight, the change in fluorescence during the odor pulse is saturated, and thus the differences in neuronal activity during and after the odor pulse are less pronounced. This would also mean that lower firing frequencies are represented more effectively by ArcLight compared with higher firing frequencies. However, we show that voltage imaging using ArcLight can readily detect postpulse sustained neuronal activity induced by increasing odor concentrations (Fig. 2F,G). The sustained peripheral response to such stimuli raises questions of whether, and how, the fly accurately detects the edge of an odor plume as it exits, a stimulus feature that is essential for accurate navigation (van Breugel and Dickinson, 2014).

\section{Temporal sharpening of odor-evoked voltage responses in OSN presynaptic terminals}

All OR22a-expressing OSN axons converge on the DM2 glomerulus in the $A L$, where their presynaptic terminals provide input to DM2-specific projection neurons (PNs; 
A

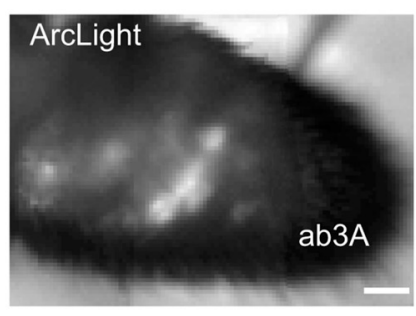

B

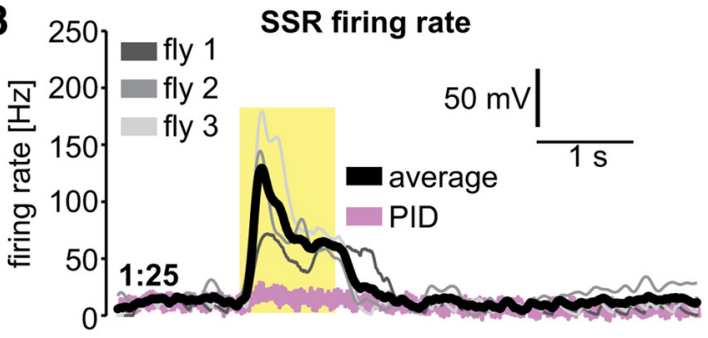

D

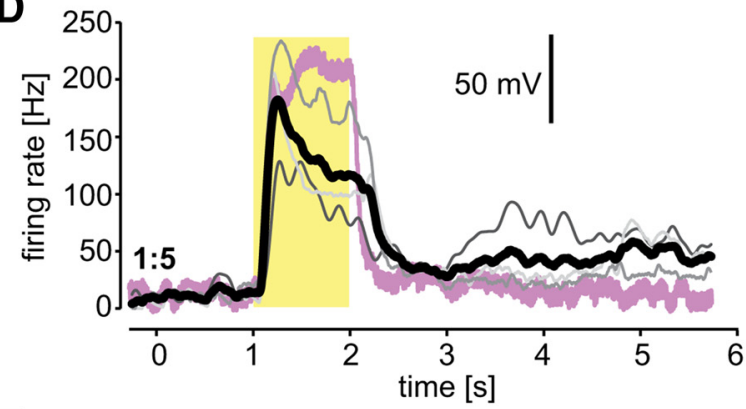

$\mathbf{F}$

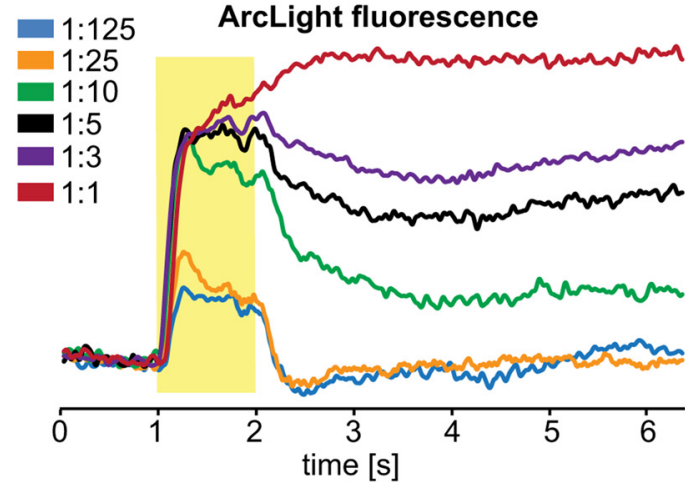

C ArcLight fluorescence

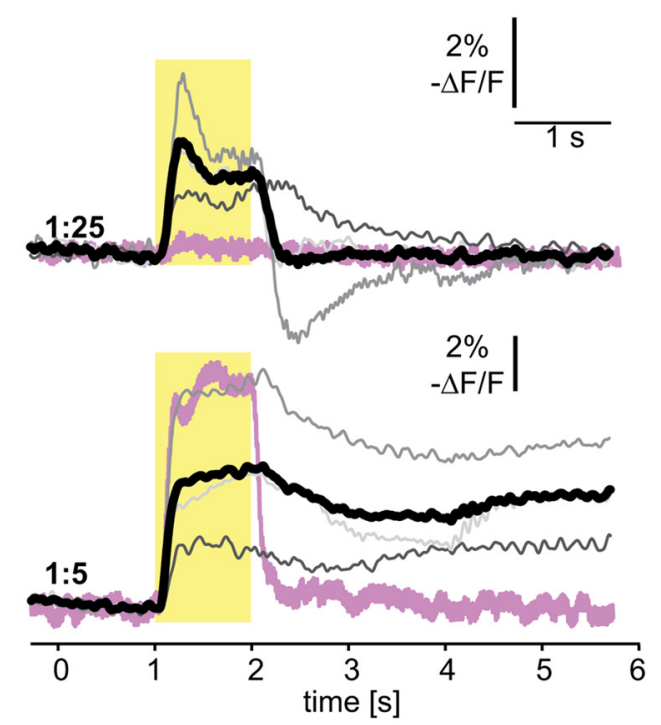

G

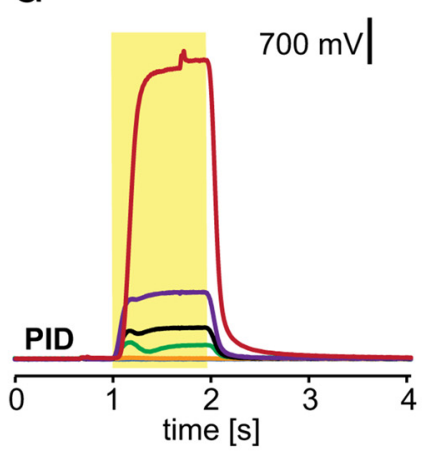

Figure 2. Optical electrophysiology reveals sustained peripheral OSN responses. $\boldsymbol{A}$, Combined fluorescent and transmitted light image of the antenna of a fly expressing ArcLight in OR22a-expressing OSNs. Scale bars, $20 \mu \mathrm{m}$. $\boldsymbol{B}-\boldsymbol{E}$, Simultaneous SSR of ab3 and voltage imaging of the antenna of three flies expressing ArcLight in OR22a-expressing OSNs. Representative PID signals are shown and were measured $\sim 2-4 \mathrm{~mm}$ behind the fly. Yellow boxes indicate odor pulse duration. $\boldsymbol{F}$, Mean ArcLight signals $(n=4)$ in response to $1 \mathrm{~s}$ Eb pulses at the indicated gas-phase dilutions. $\mathbf{G}$, Mean PID signals for the odor pulses in $\boldsymbol{F}$, measured at the fly.

Couto et al., 2005). To determine the odor-induced synaptic inputs provided to these PNs, we directly measured odor responses of the presynaptic terminals of the OR22a-expressing OSNs with ArcLight imaging (Fig. $3 A-C)$. In contrast to the sustained peripheral responses of OSNs upon termination of high-intensity Eb pulses (Figs. 1, 2), OSN presynaptic responses in DM2 decline rapidly back to baseline (Fig. $3 A-D$ ). In order to compare the kinetics of DM2 presynaptic membrane electrical responses with the kinetics of intracellular presynaptic $\mathrm{Ca}^{2+}$, we used GCaMP6f, the fastest available genetically encoded $\mathrm{Ca}^{2+}$ indicator (GECl; Chen et al., 2013; Fig. 3E). At the lowest odor intensity (1:125), the kinetics of presynaptic $\mathrm{Ca}^{2+}$ are similar to the kinetics of presynaptic voltage, exhibiting a temporally restricted increase and poststimulus inhibition (Fig. 3F,G). However, at higher odor concentrations, $\mathrm{Ca}^{2+}$ responses are dramatically sustained compared with the sharp electrical responses. This difference is likely explained by the fact that ArcLight measures electrical activity of the presynaptic membrane, while GECls measure the bulk accumulation of presynaptic intracellular $\mathrm{Ca}^{2+}$. 
Table 1: Statistical evaluation

\begin{tabular}{|c|c|c|}
\hline Figure & Initial statistical test & Post hoc test \\
\hline $1 C$ & $\begin{array}{l}\text { Kruskal-Wallis one-way ANOVA, } H=21.05 \\
\qquad p<0.001\end{array}$ & $\begin{array}{l}\text { Dunn; before pulse vs } 1: 25: \mathrm{Q}=0.73, p>0.05 \text {; before pulse vs } 1: 5 \text {, } \\
1: 3,1: 1: \mathrm{Q}>2.5, p<0.05\end{array}$ \\
\hline $1 G$ & $\begin{array}{l}\text { Unpaired } t \text { test, } t=-3.27, p=0.006 \text { for } \\
\text { spontaneous firing rate and } t=-2.21, p= \\
0.049 \text { for peak firing rate }\end{array}$ & \\
\hline $3 E$ & Two-way ANOVA, $F=6.15, p=0.003$ & $\begin{array}{l}\text { Bonferroni vs peripheral voltage; at } 1: 125,1: 25,1: 10 \text { : vs presynaptic } \\
\text { voltage and presynaptic } \mathrm{Ca}^{2+}: t<1.96, p>0.09 \text {; at } 1: 5,1: 1 \text { : vs } \\
\text { presynaptic } \mathrm{Ca}^{2+}: t<1.47, p>0.29 \text {; vs presynaptic voltage: } t> \\
3.11, p<0.005\end{array}$ \\
\hline $3 /$ & Two-way ANOVA, $F=7.63, p=0.008$ & $\begin{array}{l}\text { Bonferroni; at 1:25: } t=0.55, p=0.59 \text {; at } 1: 5: t=2.09, p=0.04 \text {; at } \\
\quad 1: 3: t=2.24, p=0.03 \text {; at } 1: 1: t=0.84, p=0.41\end{array}$ \\
\hline $3 N$ & Two-way ANOVA, $F=268.5, p<0.001$ & $\begin{array}{l}\text { Bonferroni; at 1:125: } t=0.07, p=0.95 \text {; at } 1: 25: t=0.49, p=0.63 \text {; } \\
\quad \text { at } 1: 5: t=14.85, p<0.001 \text {; at } 1: 1: t=17.37, p=0<0.001\end{array}$ \\
\hline $4 G$ & $\begin{array}{l}\text { Two-way ANOVA for repeated measurements, } \\
\qquad F=42.46, p<0.001\end{array}$ & $\begin{array}{l}\text { Bonferroni; for CGP: } t=0.55, p=0.59 \text {; for PTX } t=1.28, p=0.21 \\
\quad \text { for CGP+PTX 1:5: } t=4.38, p<0.001 \text {; for CGP+PTX } 1: 3 \text { : } \\
t=8.59, p<0.001 ; \text { CGP+PTX 1:5 vs } 1: 3, t=0.27, p=1\end{array}$ \\
\hline $4 H$ & $\begin{array}{l}\text { Two-way ANOVA for repeated measurements, } \\
\qquad F=20.61, p<0.001\end{array}$ & $\begin{array}{l}\text { Bonferroni; for CGP: } t=0.03, p=0.98 ; \text { for PTX } t=1.69, p=0.1 \\
\quad \text { for CGP+PTX 1:5: } t=3.87, p<0.001 \text {; for CGP+PTX } 1: 3: \\
t=4.65, p<0.001 ; \text { CGP+PTX } 1: 5 \text { vs } 1: 3, t=3.42, p=0.008\end{array}$ \\
\hline $4 I$ & $\begin{array}{l}\text { Paired } t \text { test, } t=-3.61, p=0.011 \text { for } \\
\quad \text { maximum response and } t=2.45, p= \\
0,049 \text { for sharpness }\end{array}$ & \\
\hline $5 A$ & $\begin{array}{l}\text { Two-way ANOVA for repeated measurements, } \\
\qquad F=32.7, p<0.001\end{array}$ & $\begin{array}{l}\text { Bonferroni vs control; vs } \mathrm{GABA}_{\mathrm{B}}-\mathrm{RNAi}: t>2.81, p<0.02 \text {; vs } \\
\text { GABA }_{\mathrm{A}}-\mathrm{RNAi}: t=1.72, p=0.26 \text { at } 1: 25 \text {, otherwise } t>3.05 \\
p<0.008 \text {; vs } \mathrm{GABA}_{\mathrm{B}}+\mathrm{GABA}_{\mathrm{A}}-\mathrm{RNAi} t>2.93, p<0.012\end{array}$ \\
\hline $5 B$ & $\begin{array}{l}\text { Two-way ANOVA for repeated measurements, } \\
\qquad F=9.91, p<0.001\end{array}$ & $\begin{array}{l}\text { Bonferroni vs control; vs GABA } \mathrm{B}_{\mathrm{B}}-\mathrm{RNAi}: t<1.07, p>0.86 \text {; vs } \\
\text { GABA }_{\mathrm{A}}-\mathrm{RNAi}: t<1.13, p>0.78 ; \mathrm{vs} \mathrm{GABA}_{\mathrm{B}}+\mathrm{GABA}_{\mathrm{A}}-\mathrm{RNAi}: \\
\quad t=0.15-0.18, p=1 \text { at } 1: 125 \text { and } 1: 25 ; t=2.49, p=0.04 \text { at } 1: 5 ; \\
t=3.15, p=0.006 \text { at } 1: 3 ; t=5.12, p<0.001 \text { at } 1: 1\end{array}$ \\
\hline $5 D, F, H$ & $\begin{array}{l}\text { Two-way ANOVA for repeated measurements, } \\
\qquad F>326.31, p<0.001\end{array}$ & $\begin{array}{l}\text { Bonferroni, control vs } \mathrm{GABA}_{\mathrm{A}} \text {, values given for significant time } \\
\text { intervals indicated in figure; at } 1: 25 t>3.18, p<0.004 \text {; at } 1: 5 \\
t>3.09, p<0.006 \text {; at } 1: 3, t>2.64, p<0.025\end{array}$ \\
\hline $5 D$ & $\begin{array}{l}\text { Two-way ANOVA for repeated measurements, } \\
\qquad F>326.31, p<0.001\end{array}$ & $\begin{array}{l}\text { Bonferroni, control vs } \mathrm{GABA}_{\mathrm{B}} \text {, values given for significant time } \\
\text { intervals indicated in figure; at 1:25 } t>2.52, p<0.035\end{array}$ \\
\hline $5 F, H, J$ & $\begin{array}{l}\text { Two-way ANOVA for repeated measurements, } \\
\qquad F>326.31, p<0.001\end{array}$ & $\begin{array}{l}\text { Bonferroni, control vs } \mathrm{GABA}_{\mathrm{A}}+\mathrm{GABA}_{\mathrm{B}} \text { values given for significant } \\
\text { time intervals indicated in figure; at } 1: 5 t>2.56, p<0.03 \text {; at } 1: 3 \\
t>3.09, p<0.006 \text {; at } 1: 1 t>2.74, p<0.018\end{array}$ \\
\hline $6 G$ & Two-way ANOVA, $F=26.7, p<0.001$ & $\begin{array}{l}\text { Bonferroni vs control; vs } \mathrm{GABA}_{\mathrm{A}}-\mathrm{RNAi} \text {, at } 1: 25 \text { and } 1: 5 t=3.56 \text { and } \\
t=3.59, p=0.001 ; \mathrm{vs}_{\mathrm{ABA}}+\mathrm{GABA}_{\mathrm{B}}-\mathrm{RNAi}(+\mathrm{Dicer}), \text { at } 1: 25 \text { : } \\
t=4.72, p<0.001(t=5.11, p<0.001) ; \text { at } 1: 5: t=2.53, p= \\
0.046(t=5.32, p<0.001) ; \text { at } 1: 1: t=2.83, p<0.001(t=5.35 \\
p<0.001)\end{array}$ \\
\hline $6 H$ & Two-way ANOVA, $F=21.7, p<0.001$ & $\begin{array}{l}\text { Bonferroni vs control; vs } \mathrm{GABA}_{\mathrm{A}}-\mathrm{RNAi}(27 \mathrm{E} 2) \text {, at } 1: 25, t=3.39 \text { and } \\
t=5.74, p<0.001 ; \text { at } 1: 1 t=4.51 \text { and } t=5.31, p<0.001\end{array}$ \\
\hline $7 A$ & Two-way ANOVA, $F=7.17, p<0.001$ & $\begin{array}{l}\text { Bonferroni; differences between distances only significant for } 1: 1 \text { : } \\
0-4 \mathrm{~cm} \text { vs } 4-10 \mathrm{~cm}, t>2.98, p<0.03\end{array}$ \\
\hline $8 C$ & Two-way ANOVA, $F=12.94, p<0.001$ & $\begin{array}{l}\text { Bonferroni vs control; at } 0-1 \text { post-pulse time } t=3.49-3.52, p= \\
0.009-0.002 \text {; at } 2-3 \text { s post-pulse time, } t=3.15-3.18, p=0.007 \text {; at } \\
3-4 \text { s post-pulse time, } t=3.02, p=0.01\end{array}$ \\
\hline $8 D$ & Two-way ANOVA, $F=6.63, p<0.001$ & $\begin{array}{l}\text { Bonferroni vs control; at } 1-2 \text { s post-pulse time, } t=3.33-3.6, p= \\
0.003-0.001 \text {; at } 2-3 \mathrm{~s} \text { post pulse time, } t=2.52-2.9, p=0.047- \\
0.015 \text {; at } 3 \text { - } 4 \text { s post pulse time, } t=3.29, p=0.004\end{array}$ \\
\hline
\end{tabular}

In order to quantify temporal contrast enhancement we used a sharpness coefficient (sharpness Max $_{\text {), defined as }}$ $\left[(\Delta F / F)_{\text {Max }}-(\Delta F / F)_{1.5}\right.$ s postpulse $] /(\Delta F / F)_{\text {Max }}$. This formula represents the relative difference of neuronal activity between a time point during stimulation and afterward (1.5 s). A sharpness coefficient of 1 represents $100 \%$ temporal contrast of neuronal activity, while 0 represents no temporal contrast. The sharpness coefficient of peripheral electrical responses decreases with increasing odor intensity (Fig. $3 H$ ). In contrast, presynaptic electrical re- sponses remain equally sharp across the entire range of tested odor intensities and are significantly sharper than peripheral responses to $1: 1$ and 1:5 Eb pulses (Fig. $3 H$ ). However, a direct comparison between peripheral and presynaptic ArcLight signal is complicated by the possibility that the peripheral ArcLight signal may reflect firing frequency and receptor potential, while spikes may travel more effectively to the presynaptic terminals than slower changes in membrane potential. We therefore directly compare the sharpness of the peripheral firing rate with 
A

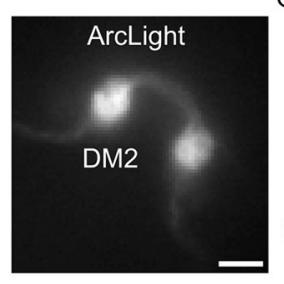

B

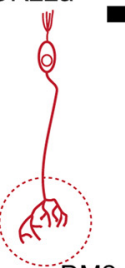

ArcLight PID
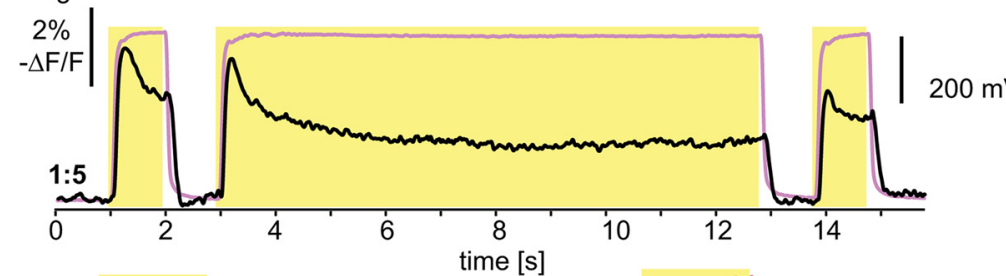

C
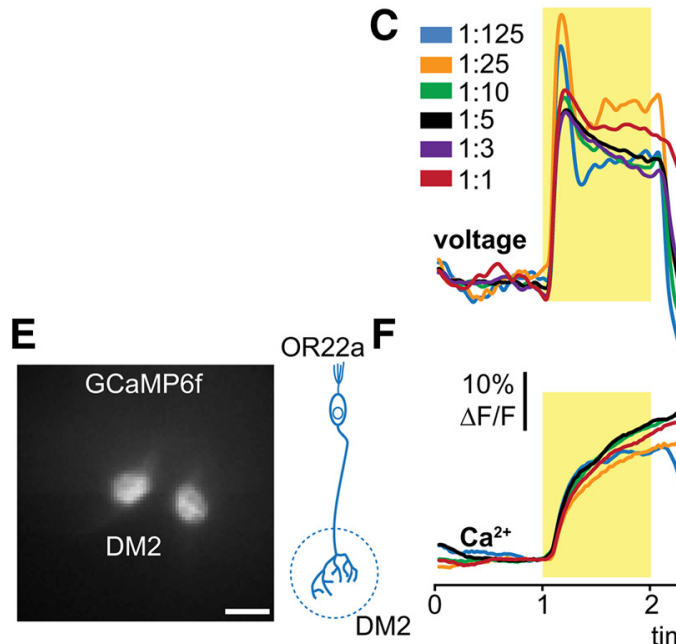

$2 \%$ $-\Delta F / F$

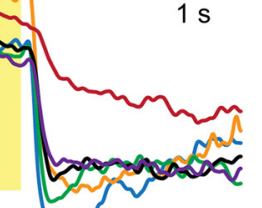

D
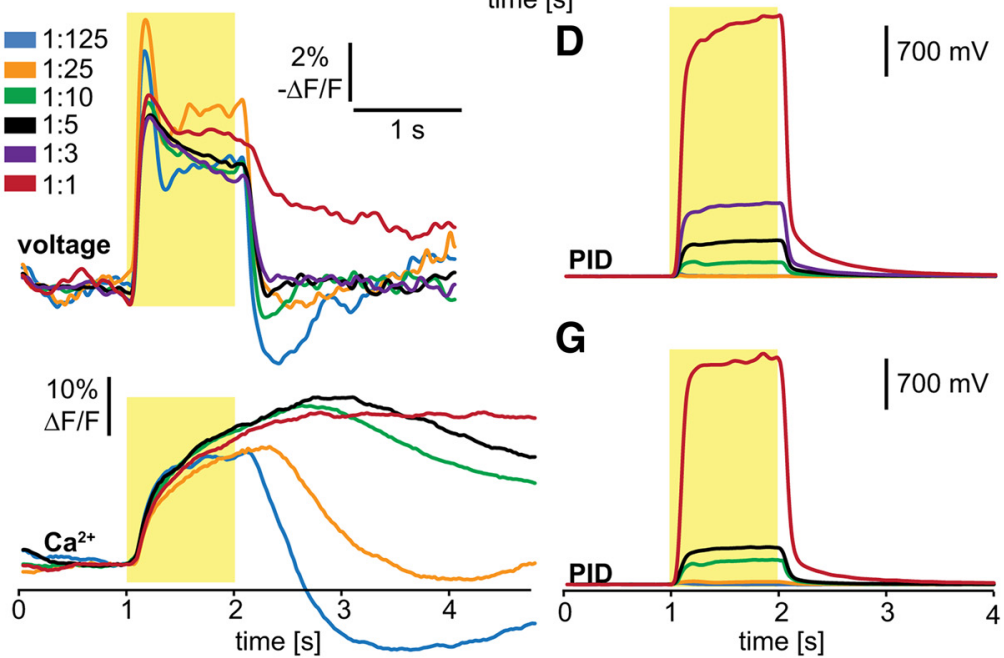

G

H
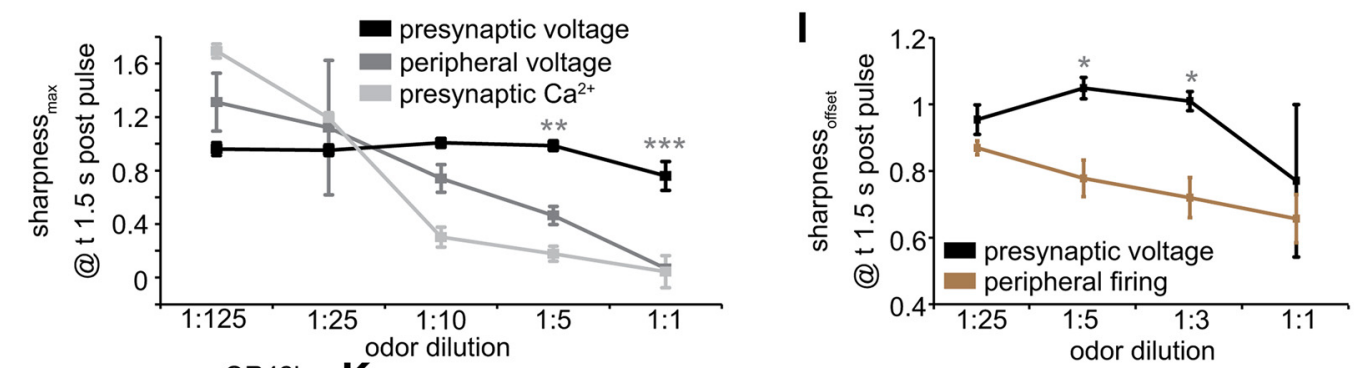

OR42b K
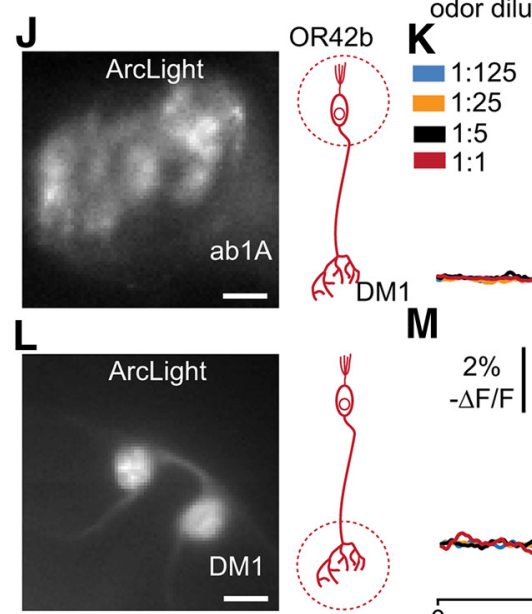

M

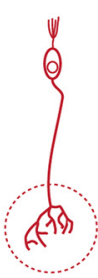

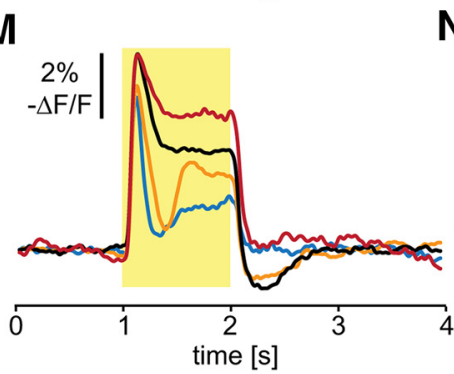

N

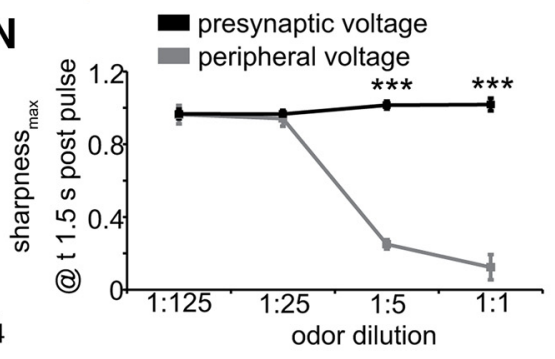

Figure 3. Optical electrophysiology of presynaptic axon terminals of OSNs indicates temporal contrast enhancement. $\boldsymbol{A}$, Fluorescent image of the antennal lobe of a fly expressing ArcLight in OR22a-expressing OSNs. Scale bars, $10 \mu \mathrm{m}$. The axon terminals of these neurons innervate the DM2 glomerulus. $\boldsymbol{B}$, Single-trial optical recording of presynaptic membrane potential in DM2 in response to pulses of 1:5 Eb, measured with the PID at the fly. Yellow boxes indicate odor pulse duration. $\boldsymbol{C}$, Mean presynaptic electrical responses $(n=5-11)$ in DM2 to $1 \mathrm{~s}$ Eb pulses of the indicated gas-phase dilutions. $\boldsymbol{D}$, Mean PID signals for the odor pulses in $\boldsymbol{C}$, measured at the fly. E, Fluorescent image of the antennal lobe of a fly expressing GCaMP6F in OR22a-expressing OSNs. Scale bar, $10 \mu \mathrm{m}$. $\boldsymbol{F}$, Mean presynaptic $\mathrm{Ca}^{2+}$ responses $(n=4-5)$ in DM2 to $1 \mathrm{~s}$ Eb pulses of the gas-phase dilutions indicated in $\mathbf{C}$. G. Mean PID signals for the odor pulses in $\boldsymbol{F}$, measured at the fly. $\boldsymbol{H}$, Sharpness coefficient based on peak amplitude $\left[(\Delta F / F)_{\text {Max }}-(\Delta F / F)_{1.5}\right.$ s postpulse $] /(\Delta F / F)_{\text {Max }}$ of OSN voltage and 


\section{continued}

$\mathrm{Ca}^{2+}$ responses in the antenna and AL. Sharpness of antennal voltage and presynaptic $\mathrm{Ca}^{2+}$ responses decreases with increasing odor concentration, while presynaptic voltage responses remain sharp, indicating the existence of a mechanism for temporal contrast enhancement of presynaptic electrical responses. Mean \pm SEM; $n=4$ for antennal voltage, $n=4-5$ for presynaptic Ca ${ }^{2+}$, and $n=5-11$ for presynaptic voltage. Statistical analysis: two-way ANOVA with Bonferroni post hoc test (antennal voltage as control); $* * p<0.01 ; * * * p$ $<0.001$. I, Sharpness coefficient based on neuronal activity at odor offset $\left[(\Delta F / F \text { or Hz })_{\text {offset }}-(\Delta F / F \text { or } \mathrm{Hz})_{1.5 \mathrm{~s} \text { postpulse }}\right] /(\Delta F / F \text { or } \mathrm{Hz})_{\text {offset }}$ comparing presynaptic voltage and peripheral firing rate of OSNs also indicates presynaptic contrast enhancement. Statistical analysis: two-way ANOVA with Bonferroni post hoc test; $* p<0.05$. $\boldsymbol{J}$, Fluorescent image of the antenna of a fly expressing ArcLight in OR42b-expressing OSNs. Scale bars, $10 \mu \mathrm{m}$. $\boldsymbol{K}$, Mean peripheral electrical responses $(n=4)$ in OR42b-expressing neurons to $1 \mathrm{~s}$ Eb pulses of the indicated gas-phase dilutions. $\boldsymbol{L}$, Fluorescent image of the antennal lobe of a fly expressing ArcLight in OR42b-expressing OSNs. Scale bar, $10 \mu \mathrm{m}$. The axon terminals of these neurons innervate the DM1 glomerulus. $\boldsymbol{M}$, Mean presynaptic electrical responses $(n=6)$ in DM1 to $1 \mathrm{~s}$ Eb pulses of the indicated gas-phase dilutions. $\boldsymbol{N}$, Sharpness coefficient of peripheral voltage is reduced at high odor concentrations $(1: 5,1: 1)$, while presynaptic voltage responses remain sharp. Statistical analysis: two-way ANOVA with Bonferroni post hoc test, $* * * p<0.001$.

the presynaptic ArcLight signal (Fig. 3/). To account for the pronounced sensory adaptation, we now use a sharpness coefficient that is based on the neuronal activity at odor offset (sharpness offset $:(\Delta F / F)_{\text {offset }}-(\Delta F / F)_{1.5 \text { s post }^{-}}$ pulse $\left.] /(\Delta F / F)_{\text {offset }}\right)$. This shows that presynaptic electrical responses to $1: 5$ and $1: 3$ dilutions are significantly sharper than the peripheral firing rate (Fig. 3/), which indicates that the sustained peripheral responses observed in Or22aexpressing neurons are temporally sharpened in their presynaptic terminals in the AL. At 1:1 sustained neuronal activity is also measurable in presynaptic terminals which could indicate that temporal sharpening can only be achieved up to a specific odor intensity. To test whether sharpened presynaptic voltage responses at high odor concentrations are found in other glomeruli, we measured OR42b-expressing OSNs, whose terminals project to the DM1 glomerulus (Fig. $3 J-N$ ). While peripheral voltage responses show sustained neuronal activity at odor dilutions of $1: 5$ and 1:1 (Fig. 3K), presynaptic voltage responses are significantly sharpened at these concentrations (Fig. $3 M, N$ ). The observed presynaptic sharpening could be a general mechanism for temporal contrast enhancement to improve edge detection and plume-guided navigation. To study this putative mechanism of temporal contrast enhancement, we further focused on optical electrophysiology as well as pharmacological and genetic manipulations to directly visualize presynaptic sharpening in the presynaptic terminals.

\section{Temporal contrast enhancement is mediated by presynaptic GABA receptors}

It has recently been shown that presynaptic inhibition of Drosophila OSNs promotes broadband synaptic transmission of olfactory stimuli by overcoming frequency restrictions imposed by short-term depression (Nagel et al., 2015). Moreover, this study shows that presynaptic inhibition sharpens $\mathrm{PN}$ responses to sparse stimuli. To investigate the role of $\mathrm{GABA}_{A}$ and $\mathrm{GABA}_{B}$ receptors on the temporal sharpening of presynaptic voltage responses, we first conducted pharmacological manipulations and measured voltage responses directly in the presynaptic terminals. While pharmacological inhibition of $\mathrm{GABA}_{\mathrm{B}}$ receptors (CGP $100 \mu \mathrm{M}$ ) shows no effect on presynaptic voltage responses to a 1:5 Eb pulse (Fig. $4 A$ ), the inhibition of $\mathrm{GABA}_{\mathrm{A}}$ receptors (PTX $200 \mu \mathrm{M}$ ) appears to in- crease response magnitude (Fig. 4B). An explanation for the difference with previous studies demonstrating that CGP54626 increases neuronal activity in presynaptic terminals (Olsen and Wilson, 2008; Root et al., 2008) could be that the pharmacological inhibition of $\mathrm{GABA}_{B}$ receptors might have a larger effect on presynaptic $\mathrm{Ca}^{2+}$ and synaptic transmission than on presynaptic voltage. Interestingly, simultaneous pharmacological inhibition of $\mathrm{GABA}_{\mathrm{A}}$ and $\mathrm{GABA} \mathrm{A}_{\mathrm{B}}$ receptors induces prolonged presynaptic voltage responses to $1: 5$ and $1: 3$ Eb pulses (Fig. $4 C, E$ ), while odor kinetics are unaltered between the measurements (Fig. 4D,F). Quantification of peak response magnitude and sharpness indicates that only the simultaneous pharmacological inhibition of $\mathrm{GABA}_{A}$ and $\mathrm{GABA}_{B}$ receptors significantly increases amplitude (Fig. 4G) and reduces sharpness of OSN presynaptic voltage responses (Fig. 4H), which also demonstrates the effectiveness of both CGP54626 and PTX. This is consistent with the previous finding that disinhibition in the AL is poorly achieved by either CGP54626 or PTX alone but is fully achieved by the simultaneous application of these drugs (Olsen and Wilson, 2008). In general, the conclusion of this experiment is consistent with the finding that presynaptic inhibition in OSN terminals is mediated by $\mathrm{GABA}_{A}$ and $G_{A B A}$ receptors (Olsen and Wilson, 2008). The more severe disruption of presynaptic sharpening for $1: 3 \mathrm{~Eb}$ pulses than for 1:5 (Fig. 4H) is consistent with the concentration-dependent sharpness of peripheral responses (Fig. 2F). Sustained activity after the blocking of presynaptic inhibition is higher than one would expect based on the sustained peripheral firing rates (Fig. 1). This might be because low-frequency firing is better reflected by ArcLight in comparison to high-frequency firing. It could also be that it is not only spiking activity but also slow changes in membrane potential that travel to the presynaptic terminals and underlie presynaptic inhibition. This hypothesis is supported by the substantially prolonged $\mathrm{Ca}^{2+}$ kinetics we observe in the presynaptic terminals. Our pharmacological studies suggest that both $G_{A B A}$ and $G A B A_{B}$ receptors mediate the presynaptic inhibition of OSNs to implement temporal contrast enhancement of sustained peripheral responses. To test whether the combined activity of $\mathrm{GABA}_{A}$ and $\mathrm{GABA}_{B}$ receptors can mediate temporal contrast enhancement in other glomeruli, we measured presynaptic voltage re- 
A

DM2 GABA $_{B}$ antagonist
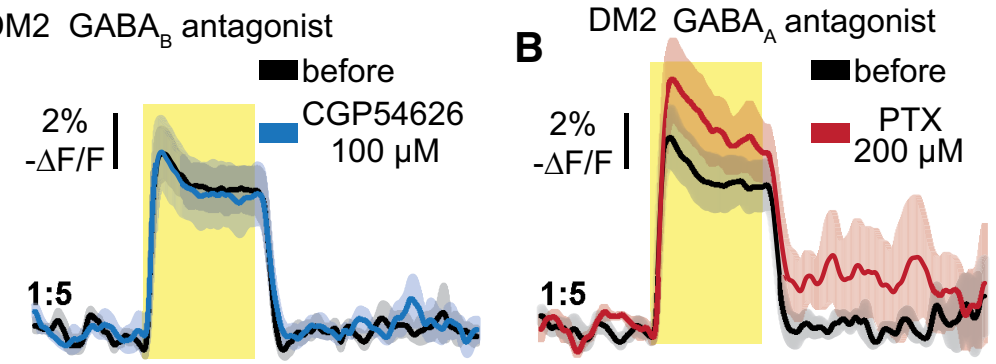

C

$\mathrm{DM} 2 \mathrm{GABA}_{\mathrm{A}}+\mathrm{GABA}_{\mathrm{B}}$ antagonists

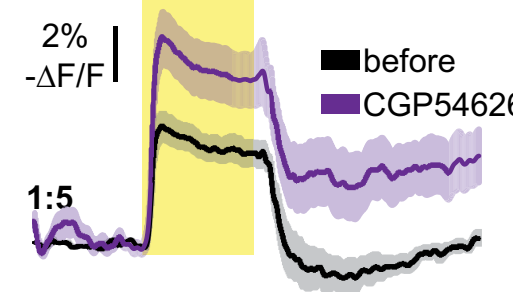

D

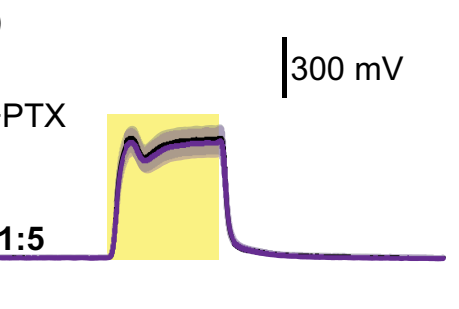

E

DM2 $\mathrm{GABA}_{\mathrm{A}}+\mathrm{GABA}_{\mathrm{B}}$ antagonists

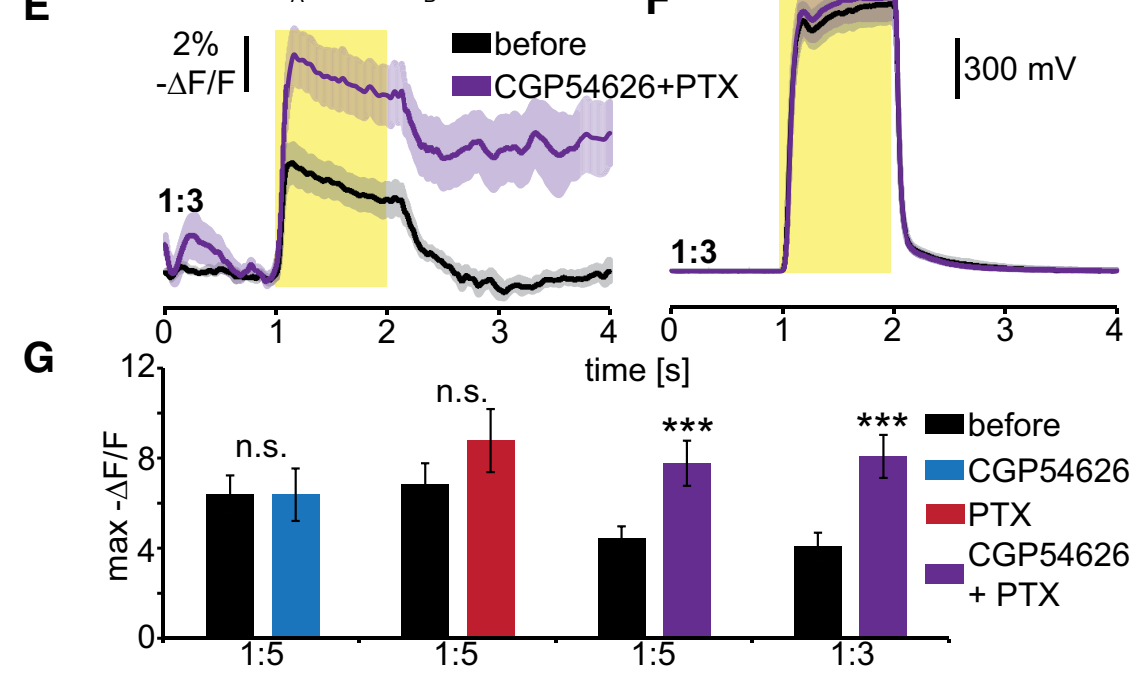

F

H

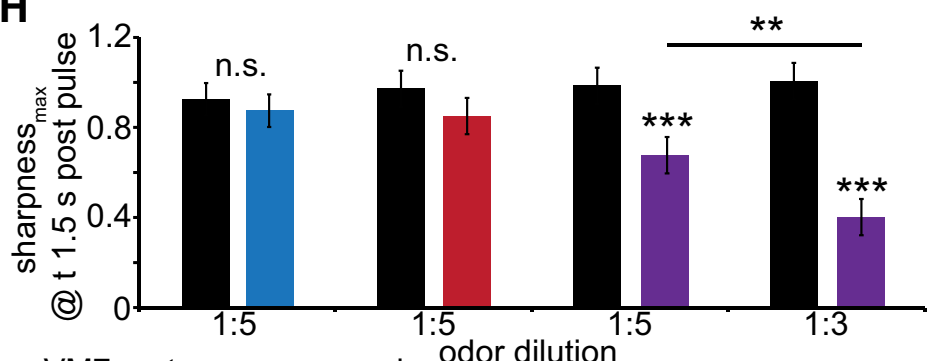

I

VM7 antennae removed
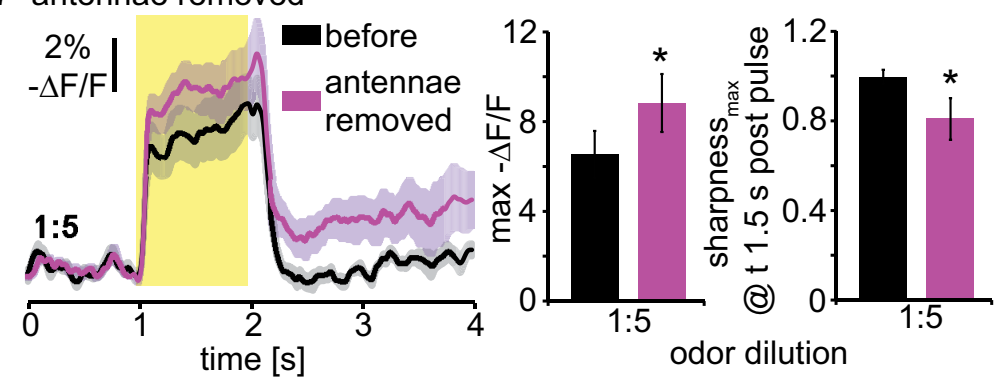

Figure 4. Temporal contrast enhancement in OSN presynaptic terminals is mediated by $\mathrm{GABA}_{A}$ and $\mathrm{GABA}_{B}$ receptors. $\boldsymbol{A}$, Pharmacological inhibition of $\mathrm{GABA}_{B}$ receptors with CGP54626 has no effect on presynaptic electrical responses of OR22a- 
continued

expressing OSNs in DM2 to a $1 \mathrm{~s}$ pulse of 1:5 Eb. Mean $\pm \mathrm{SEM} ; n=5$. $\boldsymbol{B}$, Pharmacological inhibition of GABA $\mathrm{A}_{\mathrm{A}}$ receptors with PTX appears to slightly increase magnitude and prolong presynaptic electrical responses in DM2 to $1 \mathrm{~s}$ pulses of 1:5 Eb. Mean \pm SEM; $n=5$. $\boldsymbol{C}-\boldsymbol{F}$, Simultaneous pharmacological inhibition of $\mathrm{GABA}_{\mathrm{A}}$ and $\mathrm{GABA}_{\mathrm{B}}$ receptors increases magnitude and prolongs presynaptic electrical responses in DM2 to $1 \mathrm{~s}$ pulses of 1:5 $(\boldsymbol{C})$ and 1:3 $(\boldsymbol{E})$ Eb. Simultaneously recorded PID signals are identical before and after drug application $(\boldsymbol{D}, \boldsymbol{F})$. Mean $\pm \mathrm{SEM} ; n=9$. $\boldsymbol{G}$, Maximum presynaptic voltage responses indicate that only simultaneous pharmacological inhibition of $\mathrm{GABA}_{\mathrm{A}}$ and $\mathrm{GABA}_{\mathrm{B}}$ receptors significantly increases the magnitude of voltage responses. Mean $\pm \mathrm{SEM}$; $n=5$ for CGP54626, $n=5$ for PTX, and $n=9$ for CGP54626+PTX. Statistical analysis: two-way repeated-measures ANOVA with Bonferroni post hoc test, $* * * p<0.001$. $\boldsymbol{H}$, Sharpness coefficient indicates that only simultaneous inhibition of $\mathrm{GABA}_{\mathrm{A}}$ and $\mathrm{GABA}_{\mathrm{B}}$ receptors significantly reduces the temporal contrast enhancement of presynaptic voltage responses. The sharpness of responses to $1: 3 \mathrm{~Eb}$ is reduced significantly more than that to $1: 5 \mathrm{~Eb}$, which is consistent with the larger sustained peripheral response to $1: 3 \mathrm{~Eb}$ (Fig. 2F). Mean \pm SEM; $n=5$ for CGP54626, $n=5$ for PTX and $n=9$ for CGP54626+PTX. Statistical analysis: two-way repeated-measures ANOVA with Bonferroni post hoc test, $* * p<0.01 ; * * * p<0.001$. I, Removal of the antennae reduces lateral inhibition of the maxillary palp glomerulus VM7 (Olsen and Wilson, 2008). In response to 1:5 Eb, removal of the antennae increases presynaptic voltage responses and reduces sharpness. Mean \pm SEM; $n=7$. Statistical analysis: paired $t$ test, $* p<0.05$.

sponses of OR42a-expressing OSNs, which reside in the maxillary palps and whose terminals project to the VM7 glomerulus (Fig. 4/). For VM7, lateral inhibition can be reduced by removal of the antennae which increases odor responses in VM7 PNs (Olsen and Wilson, 2008). This disinhibition can be mimicked only by simultaneous blockage of $\mathrm{GABA}_{A}$ and $\mathrm{GABA}_{\mathrm{B}}$ receptors (Olsen and Wilson, 2008), suggesting that both receptors are present at the presynaptic terminals of OR42a-expressing OSNs. We find that removal of the antennae increases presynaptic voltage responses to $1: 5 \mathrm{~Eb}$ and also reduces presynaptic sharpening (Fig. 4/). This suggests that the implementation of temporal contrast enhancement via the combined activity of presynaptic $\mathrm{GABA}_{A}$ and $\mathrm{GABA}_{B}$ receptors is a general phenomenon in the Drosophila AL. However, our findings do not rule out the possibility that $\mathrm{GABA}_{\mathrm{A}}$ - and/or $\mathrm{GABA}_{\mathrm{B}}$-mediated inhibition of other neurons in the $A L$ olfactory network are involved.

To address this issue, we genetically suppressed GABA receptor expression in OSNs innervating a single glomerulus by expressing GABA receptor-directed RNAi hairpin constructs using OR-GAL4 drivers, and measured the effects on odor-induced presynaptic electrical responses of OR22a-expressing OSNs (Fig. 5). As a control for possible nonspecific RNAi effects, we expressed RNAi directed against the neuropeptide PDF, which is not expressed in OSNs. To achieve RNAi-mediated knockdown of $\mathrm{GABA}_{A}$ or $\mathrm{GABA}_{B}$ receptors, we individually expressed either GABA $A_{A}-$ RNAi (8-10G; Liu et al., 2007, 2009) or $\mathrm{GABA}_{B}-\mathrm{R} 2-\mathrm{RNAi}$ (Root et al., 2008), respectively, in OR22a-expressing OSNs. Each of these RNAi lines has previously been established to effectively downregulate their corresponding GABA receptor subtypes (Liu et al., 2007, 2009; Root et al., 2008). Individual and simultaneous knockdown of $\mathrm{GABA}_{A}$ or $\mathrm{GABA}_{B}$ receptors increases the peak magnitude of presynaptic voltage responses (Fig. 5A). Consistent with our pharmacological results, only simultaneous knockdown of $\mathrm{GABA}_{\mathrm{A}}$ and $\mathrm{GABA}_{\mathrm{B}}$ receptors reduces the sharpness of presynaptic voltage responses (Fig. 5B). To investigate at what time after the odor offset knockdown of GABA receptors affect presynaptic contrast enhancement, we performed a timedependent analysis of the sharpness coefficient (sharpness $_{\text {offset }}$; Fig. $5 C-J$ ). Interestingly, knockdown of GABA receptors increases sharpness during the immediate postpulse hyperpolarization phase (Fig. 5D,F,H). This could be a result of increased $\mathrm{GABA}_{B}$ receptor activity, which could be due to homeostatic processes triggered by the downregulation of $\mathrm{GABA}_{A}$ receptors. This hypothesis is supported by the finding that knockdown of $G_{A B A}$ receptors, and the simultaneous knockdown of $G_{A B A}$ and $G A B A_{B}$ receptors, significantly reduce sharpness during the immediate postpulse hyperpolarization phase (Fig. 5D). Sharpness of sustained neuronal activity, which occurs only at higher intensities, is reduced only by the simultaneous knockdown of $\mathrm{GABA}_{A}$ and $\mathrm{GABA}_{B}$ receptors (Fig. $5 F, H, J$ ). For $1: 5$ and 1:3 dilutions, sharpness is reduced during a very narrow time window of 1.02 and $1.84 \mathrm{~s}$ after the odor offset (Fig. 5F,H). For 1:1 dilution, the already prolonged neuronal activity in the control is further increased with simultaneous knockdown of $\mathrm{GABA}_{A}$ or $G_{A B A_{B}}$ receptors and leads to reduced sharpness $1.3 \mathrm{~s}$ after odor offset (Fig. $5 /, J)$. These cell-specific genetic manipulations establish that the activity of both $\mathrm{GABA}_{\mathrm{A}}$ and $G A B A_{B}$ receptors expressed by the OSNs innervating a single glomerulus increase the temporal contrast of presynaptic responses to high-intensity odor stimuli.

\section{Presynaptic inhibition of OSNs accelerates behavioral responses to odor offset}

We next sought to determine whether presynaptic inhibition of OSNs influences the time course of innate behavioral responses to time-varying olfactory stimuli. We used automated fly tracking software adapted from opensource code (see Materials and Methods) to track the locomotor responses of walking flies to Eb pulses delivered from an odor port into a circular arena containing 30-50 flies. To properly compare the behavioral experiments with the physiological experiments in Figure 5, we used the same control expressing PDF-RNAi (without ArcLight). This is advantageous over using inbred parental lines as inbreeding can affect locomotor activity (Manenti et al., 2015). Although we use the same odor dilutions as in the physiological experiments, the odor intensities that the flies experience could be quite different due to distance from the odor port and the fact that the behavioral arena is closed. To quantify attractive or aversive responses, we calculated the distance of each fly from the 


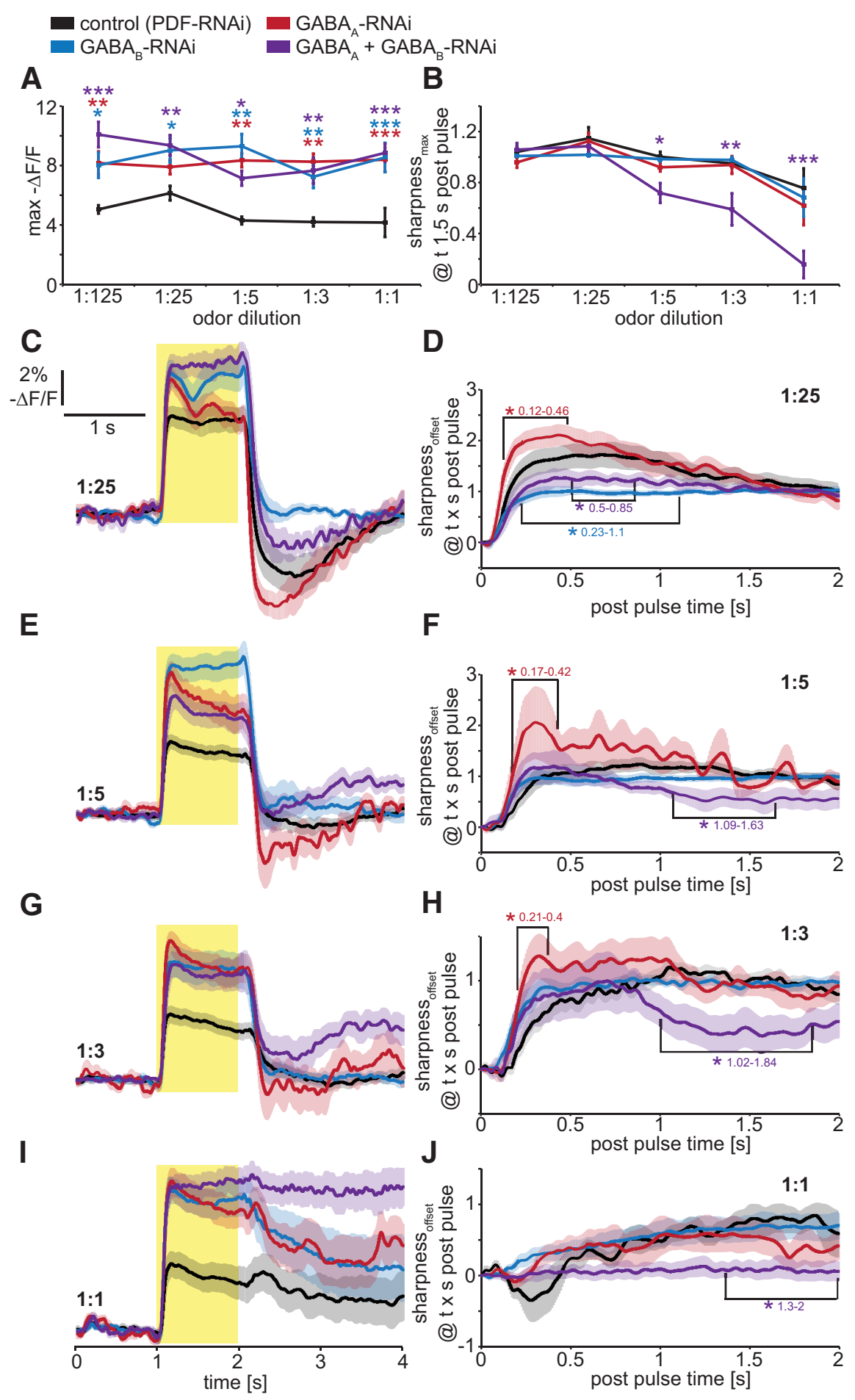

Figure 5. Temporal contrast enhancement in OSN presynaptic terminals is mediated by presynaptic $\mathrm{GABA}_{A}$ and $\mathrm{GABA}_{B}$ receptors as demonstrated by cell-specific RNAi-mediated knockdown. $\boldsymbol{A}$, Maximum presynaptic voltage responses are increased by individual and simultaneous RNAi-mediated knockdown of $\mathrm{GABA}_{\mathrm{A}}(8-10 \mathrm{G})$ and $\mathrm{GABA}_{\mathrm{B}}$ receptors. Mean $\pm \mathrm{SEM}$; $n=8$. Statistical analysis: two-way repeated-measures ANOVA with Bonferroni post hoc test (asterisks are color coded to indicate pairwise comparisons vs control), $* p<0.05 ; * * p<0.01 ; * * * p<0.001$. $\boldsymbol{B}$, Temporal contrast enhancement of DM2 presynaptic voltage responses is unaffected by RNAi-mediated knockdown of either GABA $_{A}$ (8-10G) or GABA $A_{B}$ receptors individually in OR22a-expressing OSNs. Simultaneous knockdown of $\mathrm{GABA}_{\mathrm{A}}$ (8-10G) and $\mathrm{GABA}_{\mathrm{B}}$ receptors reduces temporal contrast enhancement at odor intensities of 1:5 and higher. Mean $\pm \mathrm{SEM} ; n=8$. Statistical analysis: two-way repeated-measures ANOVA with Bonferroni post hoc test, $* p<0.05$; $* * p<0.01 ; * * * p<0.001$. C, $\boldsymbol{E}, \mathbf{G}, \boldsymbol{I}$, Presynaptic DM2 voltage responses to $1 \mathrm{~s}$ Eb pulses of gas-phase dilutions 1:25 (C), 1:5 (E), 1:3 (G), and 1:1 (I) in flies expressing either, or both, GABA A (-10G) and GABA - RNAi in OR22a-expressing OSNs. Mean \pm SEM; $n=$ 8-10. $\boldsymbol{D}, \boldsymbol{F}, \boldsymbol{H}, \boldsymbol{J}$, Time-dependent sharpness coefficient to analyze the time window in which GABA receptor knockdown affects 
continued

contrast enhancement. After a 1:25 pulse $(\boldsymbol{D})$ knockdown of $\mathrm{GABA}_{\mathrm{B}}$ receptors and simultaneous knockdown of $\mathrm{GABA}$ (8-10G) and $G_{A B A}$ receptors affect sharpness during the hyperpolarization phase immediately after odor offset. Knockdown of $\mathrm{GABA}_{A}$ receptors leads an increase in postpulse hyperpolarization for 1:25 (D), 1:5 $(\boldsymbol{F})$, and 1:3 $(\boldsymbol{H})$. Contrast enhancement of sustained activity later than $1 \mathrm{~s}$ after the odor offset is only achieved by simultaneous knockdown of GABA $A_{A}$ and GABA $A_{B}$ receptors in OR22a-expressing OSNs, indicating a combined role for these receptors. Statistical analysis: two-way repeated-measures ANOVA with Bonferroni post hoc test, $* p<0.05$.

odor port over time, relative to its initial position at the beginning of each trial. Ten second pulses of 1:125 Eb induce attraction, with flies moving closer to the odor port (Fig. 6A). In contrast, $10 \mathrm{~s}$ pulses of 1:1 Eb induce avoidance, with flies moving away from the odor port (Fig. 6B). This is consistent with the previous observation that low concentrations of Eb solely activate OSNs mediating innate attraction, while higher concentrations recruit additional OSNs mediating innate avoidance (Semmelhack and Wang, 2009). Control flies expressing PDF-RNAi in OR22a-expressing OSNs innervating DM2 are attracted to pulses of 1:125 and 1:25 Eb (Fig. 6C,D). Flies expressing $\mathrm{GABA}_{A}-\mathrm{RNAi}$ (8-10G) alone or simultaneously expressing $G_{A B A}-R N A i(8-10 G)$ and $G_{A} A B A_{B}-R N A i$ exhibit reduced attraction (Fig. $6 C, D$ ). Control flies are neither attracted nor repelled by pulses of 1:5 Eb (Fig. 6E), consistent with the interpretation that this intensity of $\mathrm{Eb}$ stimulates OSNs mediating attraction and avoidance to a relative extent that counterbalances behavioral responses. In stark contrast to control flies, $G_{A B A}-R N A i$ (8-10G) and GABA $_{A}-$ RNAi (8-10G) + GABA $_{B}$-RNAi flies are repelled by $1: 5$ Eb pulses (Fig. $6 E$ ). All flies, regardless of genotype, are strongly repelled by pulses of $1: 1 \mathrm{~Eb}$, with increased avoidance in $\mathrm{GABA}_{A}-\mathrm{RNAi}$ (8-10G) + $\mathrm{GABA}_{\mathrm{B}}-\mathrm{RNAi}$ flies (Fig. 6 F). Avoidance of $1: 5$ and $1: 1$ dilutions is even stronger in flies expressing Dicer together with $\mathrm{GABA}_{A}-\mathrm{RNAi}(8-10 \mathrm{G})+\mathrm{GABA}_{B}-\mathrm{RNAi}$, which underlines the specificity of the behavioral changes. Statistical analysis supporting these conclusions is shown in Figure $6 G$. The expression of a different $G_{A B A}-R N A i$ (2-7E2; Liu et al., 2009) in OR22a-expressing OSNs also increases avoidance (Fig. $6 H$ ), supporting the specificity of these $G_{A B A}-R N A i$ effects. In light of the study by Semmelhack and Wang (2009), who did not observe any changes in valence after silencing DM2, our findings of increased presynaptic electrical activity in DM2 leading to increased avoidance could be explained by altered network activity. Increased activity in DM2 mediated by the knockdown of GABA $A_{A}$ receptors (Fig. 5) could, for example, increase lateral inhibition, which could affect other glomeruli, leading to increased avoidance.

These sustained attractive and aversive responses to $10 \mathrm{~s}$ odor pulses likely reflect chemotactic responses to steady-state odor gradients in the olfactory arena. To probe the effects of presynaptic OSN inhibition on the perception of a time-varying stimulus, we delivered $1 \mathrm{~s}$ odor pulses and focused our attention on behavioral responses during and after termination of the pulse (Figs. 7 , 8). Responses of individual flies to brief odor pulses depend heavily on odor dilution and the initial distance from the odor port at the time of odor onset (Fig. $7 A, B$ ). Flies that are initially close to the odor port avoid it, while flies that are initially far away do not respond. We focused on the high odor intensities and used the PID to measure odor dynamics within the behavioral arena (Fig. 7C,D). Interestingly, within $3 \mathrm{~cm}$ of the odor port flies experience odor dynamics in a way that is similar to entering and exiting of a plume, with a rapid increase of odor intensity and a fast decline. More than $3 \mathrm{~cm}$ away from the odor port, the changes in odor intensity are more gradual. To visualize this, we calculated tau, which represents the time taken from the peak PID value to $36.8 \%$ of the PID value (Fig. $7 E, F$ ). To study the behavior of flies upon exiting plume-like odor dynamics, we focused on those flies whose initial position was within $3 \mathrm{~cm}$ from the odor port (Fig. 8A-D).

Immediately after a $1 \mathrm{~s}$ odor pulse $(0-1 \mathrm{~s}$ postpulse time) of $1: 5 \mathrm{~Eb} \mathrm{GABA}_{\mathrm{A}}-\mathrm{RNAi}$ (8-10G) or $\mathrm{GABA}_{A}-\mathrm{RNAi}$ (8-10G) plus $\mathrm{GABA}_{B}-\mathrm{RNAi}$ (plus Dicer) in OR22aexpressing OSNs, innervating DM2 increases velocity away from the odor port (Fig. $8 A, C$ ). This likely reflects increased avoidance, which was also shown for the $10 \mathrm{~s}$ odor pulse (Fig. $6 \mathrm{G}$ ). The velocity between 2 and $4 \mathrm{~s}$ after termination of the odor pulse remains significantly higher only in flies expressing $\mathrm{GABA}_{A}-\mathrm{RNAi}(8-10 \mathrm{G})$ and $\mathrm{GABA}_{B}-$ RNAi flies (Fig. $8 C$ ). Control flies exhibit stronger avoidance response to pulses of $1: 1 \mathrm{~Eb}$ than to those of $1: 5 \mathrm{~Eb}$, and, interestingly, this avoidance terminates rapidly upon termination of the pulse (Fig. $8 B, D$ ). As the neuronal activity of DM2 presynaptic terminals to $1: 1$ odor pulses would suggest an even more prolonged avoidance, this could demonstrate how the activity of multiple glomeruli is used to balance and switch innate behavior between attraction and avoidance. However, while GABA receptor knockdown does not affect avoidance during or immediately after the 1:1 Eb pulse, simultaneous knockdown of $G_{A B A}$ and $G_{A B A}$ receptors prolongs avoidance between 1 and $4 \mathrm{~s}$ after termination of the odor pulse (Fig. $8 D$ ). In contrast, GABA receptor knockdown did not affect flies that are $>3 \mathrm{~cm}$ away from the odor port and experience a more gradual change in odor dynamics (Fig. 8E,F). This suggests that the combined activity of presynaptic $G_{A B A}$ and $G A B A_{B}$ receptors, which mediates gain control and temporal contrast enhancement in olfactory sensory neurons, enhances detection of the termination of the odor pulse.

\section{Discussion}

Lateral inhibition in the visual system improves environmental perception by enhancing contrast vision to enable accurate spatial edge detection (Kuffler, 1953; Buldyrev and Taylor, 2013). Temporal edge detection in the audi- 

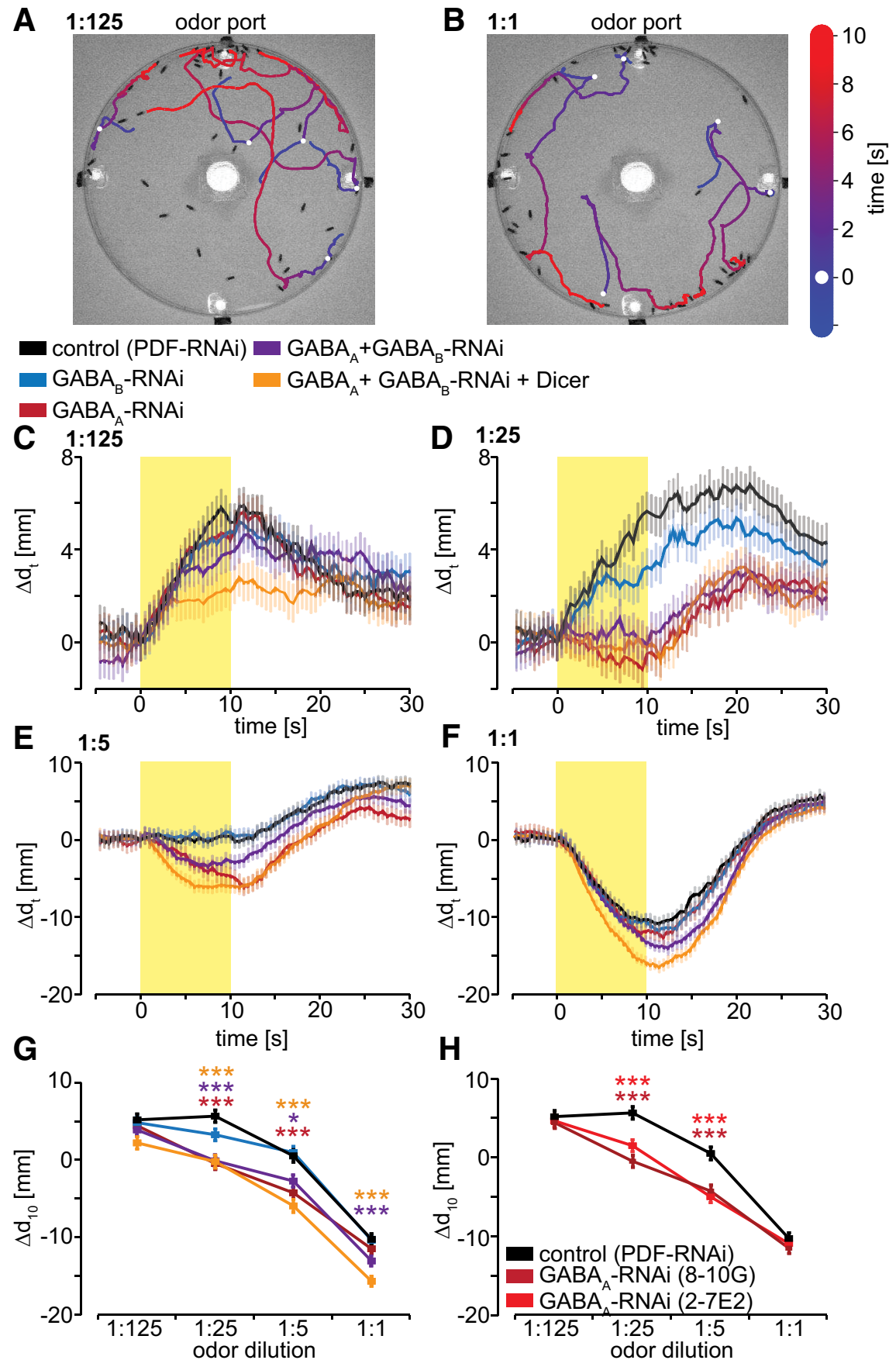

Figure 6. Presynaptic OSN GABA receptors affect innate olfactory attraction and avoidance. $\boldsymbol{A}, \boldsymbol{B}$, Representative trajectories of control flies (PDF-RNAi) in the olfactory arena. The white dot indicates the position of the fly at the beginning of the $10 \mathrm{~s}$ odor pulse. The odor enters the arena from the top odor port. Trajectories indicate movement toward the odor port during a $10 \mathrm{~s} 1: 125 \mathrm{~Eb}$ pulse $(\boldsymbol{A})$, and away from the odor port during a 1:1 Eb pulse $(\boldsymbol{B})$. C , $\boldsymbol{D}$, Behavioral responses to $10 \mathrm{~s} 1: 125(\boldsymbol{C})$ and 1:25 (D) Eb pulses. We defined $\Delta d_{t}$ as the difference in distance from the odor port between odor onset and time $t\left(\Delta d_{t}=d_{0}-d_{t}\right)$, such that positive $\Delta d_{t}$ values reflect movement toward the odor port (i.e, attraction) and negative values reflect movement away (i.e., avoidance). Control flies (PDF-RNAi) are attracted to the odor port during Eb pulses of these intensities, and this attraction is inhibited by RNAi-mediated knockdown in OR22a-expressing OSNs of $\mathrm{GABA}_{A}$ receptors individually or $\mathrm{GABA}_{\mathrm{A}}$ and $\mathrm{GABA}_{\mathrm{B}}$ receptors simultaneously. Mean \pm SEM; $\boldsymbol{E}, \boldsymbol{F}$, Control flies (PDF-RNAi) avoid the odor port during $10 \mathrm{~s}$ at 1:5 (C) and at 1:1 (D) Eb pulses, and this avoidance is increased

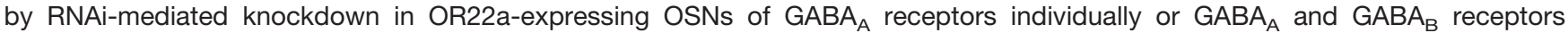
simultaneously. Mean \pm SEM; $\mathbf{G}$, Net distance moved at the end of $10 \mathrm{~s}$ Eb pulses of the indicated gas-phase dilutions. For Eb

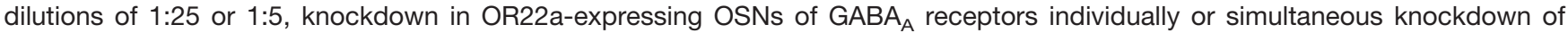
$\mathrm{GABA}_{A}$ and $\mathrm{GABA}_{\mathrm{B}}$ receptors, increases avoidance of the odor port. For Eb dilution of 1:1, only simultaneous knockdown of GABA and $\mathrm{GABA}_{\mathrm{B}}$ receptors increases avoidance. Mean $\pm \mathrm{SEM}, n=650-800$ total flies per genotype and concentration assayed in at least 10 independent experiments. Statistical analysis: two-way ANOVA followed with Bonferroni post hoc test (asterisks are color coded 
continued

to indicate pairwise comparisons vs control), $* p<0.05 ; * * * p<0.001$. $\boldsymbol{H}$, Expression of either of two different GABA $-\mathrm{RNAi}$ transgenes in OR22a-expressing OSNs increases avoidance. Mean \pm SEM. Statistical analysis: two-way ANOVA with Bonferroni post hoc test, $* * * p<0.001$.

tory system improves sound localization (Chait et al., 2008). Here we address whether similar mechanisms exist in the olfactory system that improve odor edge detection (Fig. 9, summary). We find that high-intensity odor pulses induce sustained peripheral responses in OSNs (Figs. 1, $2,9)$. We use optical electrophysiology to visualize that sustained peripheral responses undergo contrast enhancement by presynaptic GABA receptors to generate sharper responses in OSN presynaptic axon terminals in the $\mathrm{AL}$ (Figs. 4, 5, 9). Furthermore, the combined activity of presynaptic $\mathrm{GABA}_{A}$ and $\mathrm{GABA}_{\mathrm{B}}$ receptors modulates the kinetics of innate olfactory behavior after termination of an odor pulse (Figs. 8, 9).

Our voltage and $\mathrm{Ca}^{2+}$ measurements reveal contrast enhancement of presynaptic OSN electrical activity but not presynaptic intracellular $\mathrm{Ca}^{2+}$ (Fig. 3). It is possible that high odor intensities induce $\mathrm{Ca}^{2+}$ release from internal stores, resulting in sustained presynaptic $\mathrm{Ca}^{2+}$ increases (Murmu et al., 2010, 2011). Alternatively, sustained peripheral responses could activate voltage-gated $\mathrm{Ca}^{2+}$ channels along the axons of the OSNs (Murmu et al., 2010), with sustained presynaptic $\mathrm{Ca}^{2+}$ increases mirroring sustained peripheral responses. As electrical recordings from single $\mathrm{PNs}$ indicate that membrane depolarization is tightly coupled to neurotransmitter release (Nagel et al., 2015), it is likely that sharpened presynaptic voltage responses are faithfully propagated even when presynaptic intracellular $\mathrm{Ca}^{2+}$ remains high. This could be because $\mathrm{Ca}^{2+}$ indicators report bulk cytoplasmic $\mathrm{Ca}^{2+}$ in the nanomolar to micromolar range, and not the substantially higher $\mathrm{Ca}^{2+}$ transients in the $\mathrm{Ca}^{2+}$ channelassociated microdomains that drive synaptic vesicle release (Llinás et al., 1992; Oheim et al., 2006; Matkovic et al., 2013). While bulk cytoplasmic $\mathrm{Ca}^{2+}$ levels could remain elevated after a train of action potentials invade the presynaptic terminals, the microdomain concentration at synaptic release sites may have already declined below the threshold for triggering release. Consistent with this interpretation of our observations, odor stimuli eliciting sustained $\mathrm{Ca}^{2+}$ increases in OSN presynaptic terminals induce substantially more abbreviated $\mathrm{Ca}^{2+}$ increases in postsynaptic PN dendrites (Asahina et al., 2009). However, it is also possible that postsynaptic inhibition contributes to temporal sharpening of $\mathrm{PN}$ responses (Wilson and Laurent, 2005; Fujiwara et al., 2014).

Lateral inhibition in the AL has extensively been studied in different insect species. In locust, GABAergic local interneurons have been shown to synchronize oscillations between odor-coding neural assemblies in the AL (MacLeod and Laurent, 1996). In the honey bee, these synchronized oscillations have been shown to be essential for the discrimination of molecularly similar odorants (Stopfer et al., 1997). Moreover, calcium imaging studies in the honey bee have demonstrated that local interneurons mediate global inhibition in the $\mathrm{AL}$ to enhance spatial contrast between glomeruli (Sachse and Galizia, 2002). In the hawkmoth, Manduca sexta, blocking inhibition in the $\mathrm{AL}$ impairs the localization of odor sources by affecting the temporal firing pattern in PNs (Lei et al., 2009). In Drosophila it has become evident that presynaptic GABA receptors play a crucial role in mediating lateral inhibition in the AL (Olsen and Wilson, 2008; Root et al., 2008). While presynaptic GABA receptors have been shown to be essential for odor object localization (Root et al., 2008), we show that presynaptic GABA receptors also enhance temporal contrast within glomeruli to improve the detection of the temporal structures of odor plumes.

Drosophila melanogaster live, feed, and reproduce on fermenting fruits. To locate fermenting fruit, Drosophila navigate via plumes of odors (Gaudry et al., 2012; van Breugel and Dickinson, 2014). Gain control mediated by presynaptic inhibition is an important mechanism for maintaining sensitivity to a wide range of experienced odor intensities (Olsen and Wilson, 2008; Root et al., 2008). While $G A B A_{B}$-mediated presynaptic gain control is known to be important for localizing pheromone-emitting objects (Root et al., 2008), no behavioral role for presynaptic $\mathrm{GABA}_{A}$ receptors has previously been reported. Here we show that presynaptic OSN GABA Geceptors modulate innate behavioral responses to the fruit-related odor Ethyl butyrate (Eb) (Figs. 6, 8). While blocking synaptic output in DM2 was previously reported to have no behavioral consequence (Semmelhack and Wang, 2009), our RNAi-mediated $\mathrm{GABA}_{\mathrm{A}}$ knockdown results indicate that increased neuronal activity in DM2 leads to increased avoidance (Figs. 6, 8). A possible explanation could be that increased activity in DM2 alters network activity in the $\mathrm{AL}$ affecting other glomeruli that mediate attraction or aversion. Interestingly, RNAi-mediated presynaptic knockdown of $\mathrm{GABA}_{\mathrm{B}}$ receptors individually had no statistically distinguishable effect on behavioral responses to Eb (Figs. 6, 8). While $\mathrm{GABA}_{\mathrm{B}}$ receptors play an important role in sustained pheromone-related behaviors and are differentially expressed across glomeruli (Root et al., 2008), $G_{A B A}$ receptors might be more important for processing transient fruit-related odor stimuli. However, future immunohistological studies need to show the presence of presynaptic $\mathrm{GABA}_{\mathrm{A}}$ receptors and their distribution across different glomeruli. It could also be that $\mathrm{GABA}_{\mathrm{B}}$ receptors affect the $\mathrm{AL}$ network activity in a different way than $\mathrm{GABA}_{A}$ receptors. At the highest odor intensity tested, only simultaneous knockdown of $\mathrm{GABA}_{A}$ and $G A B A_{B}$ receptors in $D M 2$ increased aversive behavior (Fig. 6F,G). This demonstrates a combined role for $\mathrm{GABA}_{A}$ and $\mathrm{GABA}_{\mathrm{B}}$ receptors in mediating presynaptic inhibition as has previously been observed in physiological studies (Olsen and Wilson, 2008). Moreover, we also visualize the combined role for $\mathrm{GABA}_{A}$ and $\mathrm{GABA}_{B}$ receptors in medi- 


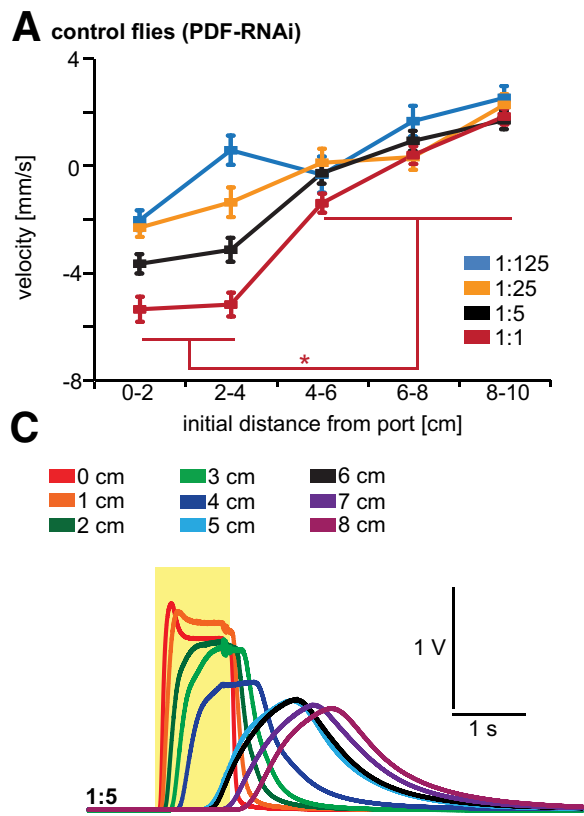

B control flies (PDF-RNAi)

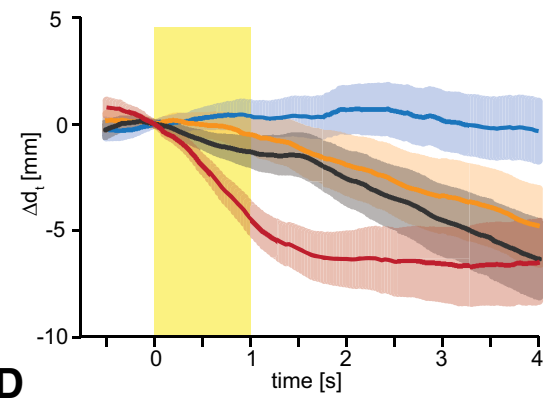

D
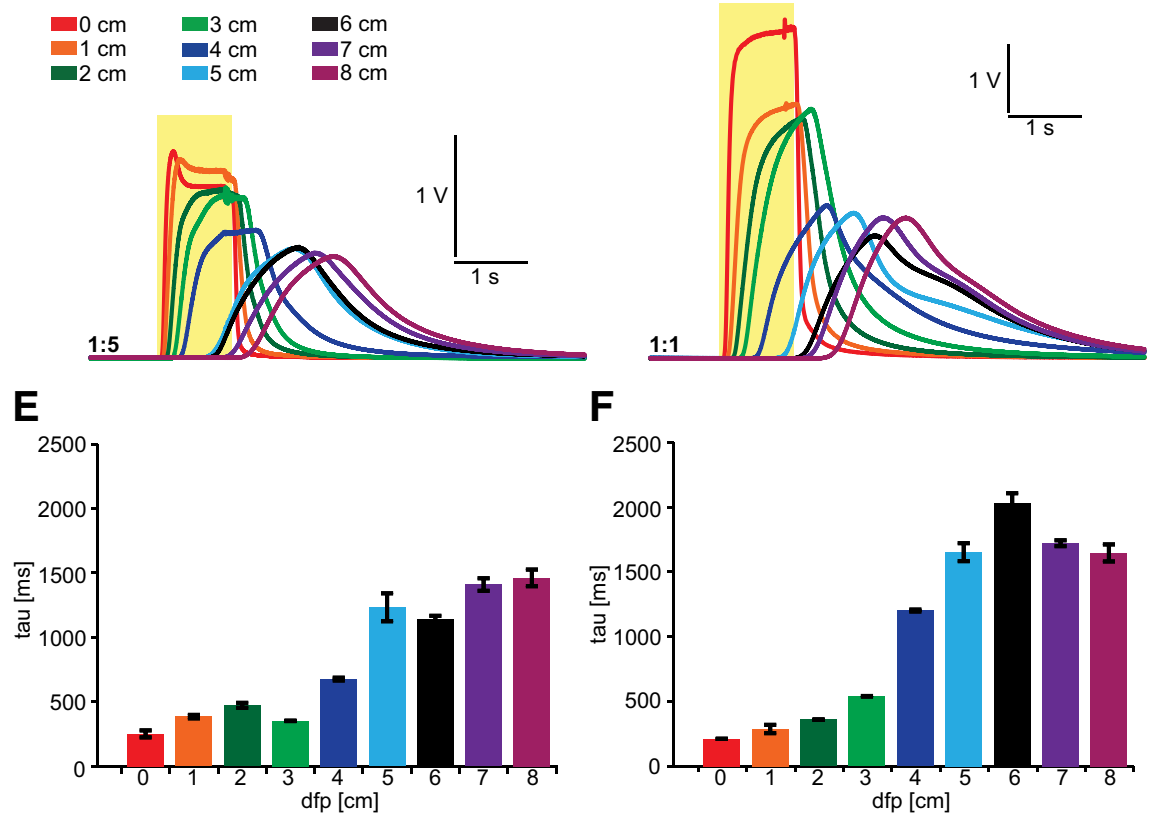

\section{$\mathbf{F}$}

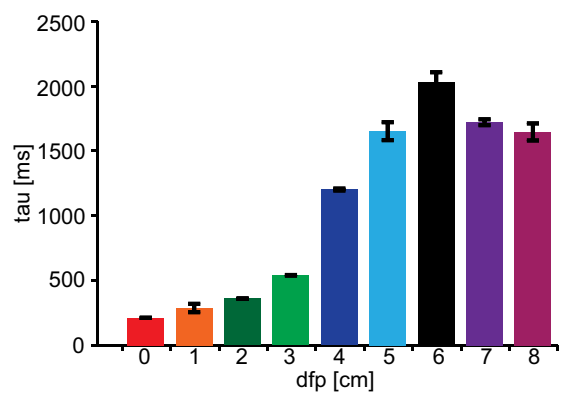

Figure 7. Behavioral responses to quick $1 \mathrm{~s}$ Eb pulses are dependent on temporal odor dynamics in the behavioral chamber. $\boldsymbol{A}$, Velocity of flies during and after $1 \mathrm{~s}$ Eb pulses is dependent on initial position within the olfactory arena at initiation of the odor pulse. Control flies expressing PDF-RNAi in OR22a-expressing neurons exhibit strong avoidance only to 1:1 Eb and only when initial position in the arena is $\leq 4 \mathrm{~cm}$ from the odor port. Mean \pm SEM; $n=116-172$ total flies per genotype and concentration assayed in at least 10 independent experiments. Statistical analysis: two-way ANOVA with Bonferroni post hoc test, $* p<0.05$. B. Behavioral responses of control flies (initial position to port $<5 \mathrm{~cm}$ ) to $1 \mathrm{~s}$ Eb pulses of gas-phase dilutions, as indicated in $\boldsymbol{A}$. Mean \pm SEM. $\boldsymbol{C}, \boldsymbol{D}$, Mean PID recordings $(n=5)$ in the behavioral chamber showing odor dynamics of 1 s odor pulses of $1: 5(\boldsymbol{C})$ and 1:1 $(\boldsymbol{D})$ that vary dependent on the distance to the odor port. $\boldsymbol{E}, \boldsymbol{F}$, Tau represents the time that the odor stimulus takes to reach $36.8 \%$ of its peak value. For $1: 5(\boldsymbol{E})$ and $1: 1(\boldsymbol{F})$, tau drastically increases after a distance of 3-4 cm from the odor port, indicating that flies within $3 \mathrm{~cm}$ from the odor port experience a fast increase and decrease in odor intensity, while flies that are $>3 \mathrm{~cm}$ away from the odor port experience more gradual changes in odor intensity. Mean \pm SEM. $n=5$.

ating temporal contrast enhancement of presynaptic electrical responses. For the first time, we link presynaptic inhibition mediating gain control and temporal contrast enhancement (Figs. 4, 5) to behavioral responses after odor pulse termination (Fig. 8). This suggests that the combined participation of $\mathrm{GABA}_{A}$ and $\mathrm{GABA}_{B}$ receptors could be an advantage for animals that encounter a very wide dynamic range of odor stimuli.

Temporal sharpening of olfactory information could also play an important role in associative learning. During associative learning in mammals and insects, temporally limited olfactory stimuli determine a critical time window for the integration of other sensory information, such as sugar as a reward or electric shock as a punishment (Tully and Quinn, 1985; Hammer and Menzel, 1995; Delamater et al., 2014). In single neurons implicated in learning,
GABAergic inhibition has been shown to truncate neuronal activity and thus has been hypothesized to define the time window for coincidence detection (Pouille and Scanziani, 2001; Mittmann et al., 2005; Raccuglia and Mueller, 2014). In fact, altering the degree of GABAergic inhibition or artificially activating GABA receptors during learning interferes with the formation of associative memories in insects (Liu et al., 2007; Liu and Davis, 2009; Raccuglia and Mueller, 2013). The GABAergic presynaptic temporal contrast enhancement we reveal here could play a role in determining a concentration-invariant critical time window for enhancing the temporal accuracy of associative memories.

How could presynaptic inhibition underlie temporal contrast enhancement? Presynaptic and postsynaptic inhibition in the AL are mediated by multiple GABAergic 
A
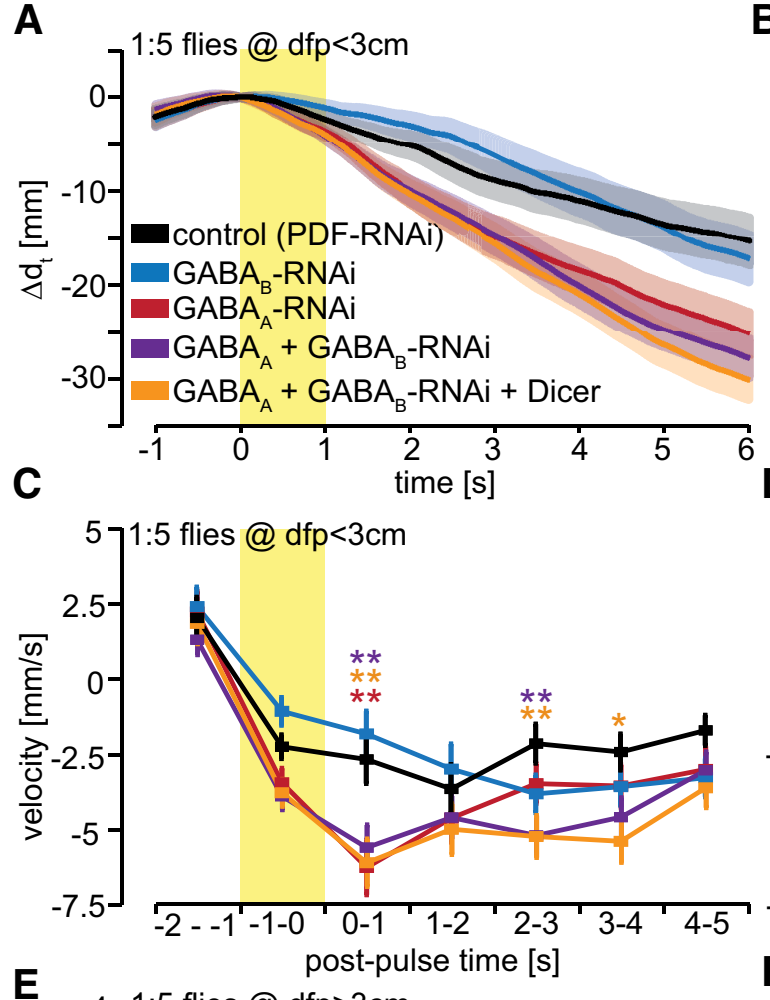

E

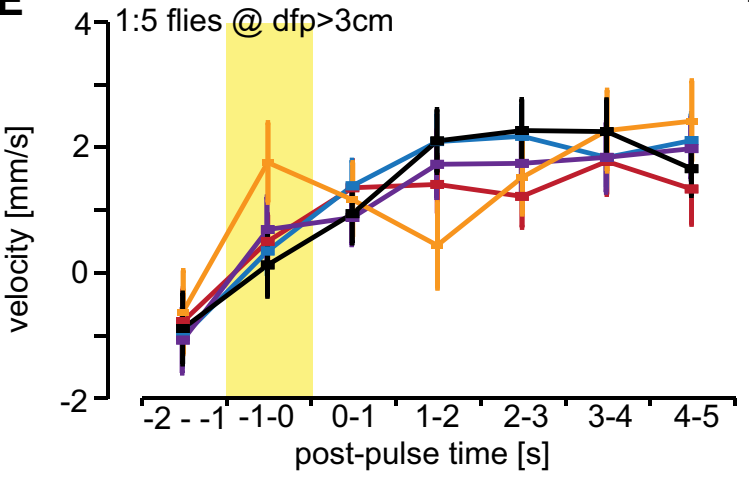

B
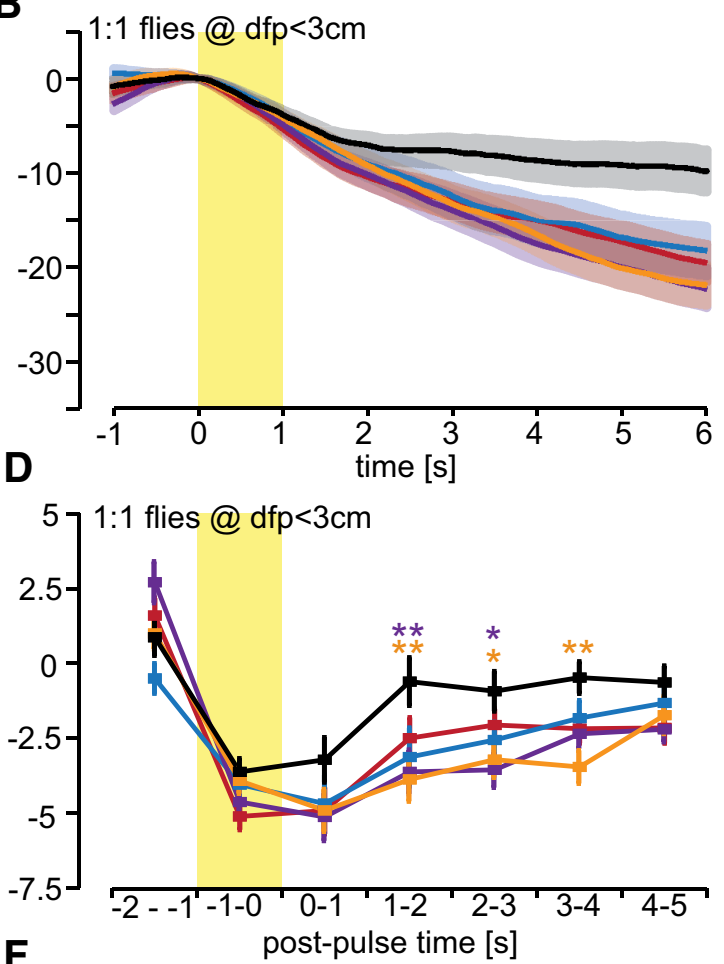

$F$

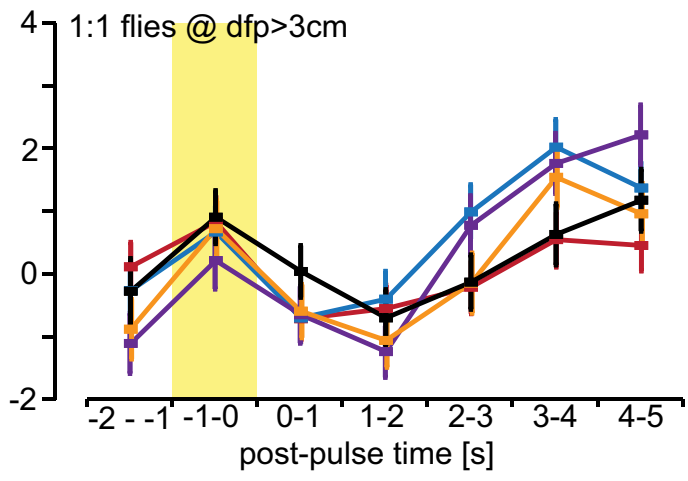

Figure 8. Presynaptic OSN GABA receptors accelerate behavioral responses to odor pulse termination. $\boldsymbol{A}, \boldsymbol{B}$, Behavioral responses of flies within $3 \mathrm{~cm}$ from the odor port show avoidance during and after a $1 \mathrm{~s}$ Eb pulse of 1:5 (A) and 1:1 (B). Mean \pm SEM; $n=$ 100-200 total flies per genotype and concentration assayed over at least 10 independent experiments. $\boldsymbol{C}$, Average velocity of flies within $3 \mathrm{~cm}$ from the odor port during and after a $1 \mathrm{~s} \mathrm{1:5} \mathrm{Eb} \mathrm{pulse.} \mathrm{During} \mathrm{and} \mathrm{immediately} \mathrm{after} \mathrm{the} \mathrm{odor} \mathrm{pulse,} \mathrm{the} \mathrm{velocity} \mathrm{away}$ from the odor port is significantly increased by individual knockdown of GABA $_{A}$ receptors and simultaneous knockdown of GABA ${ }_{A}$ and $\mathrm{GABA}_{B}$ receptors. The velocity between 2 and $4 \mathrm{~s}$ after the odor pulse is significantly increased by simultaneous knockdown of $\mathrm{GABA}_{A}$ and $\mathrm{GABA}_{\mathrm{B}}$ receptors. Statistical analysis: two-way ANOVA with Bonferroni post hoc test (asterisks are color coded to indicate pairwise comparisons vs control), $* p<0.05 ; * * p<0.01$. $\boldsymbol{D}$, Average velocity during 1:1 Eb odor pulses is unaffected by the knockdown of GABA receptors. However, simultaneous knockdown of $\mathrm{GABA}_{\mathrm{A}}$ and $\mathrm{GABA}_{\mathrm{B}}$ receptors significantly prolongs avoidance between 1 and $4 \mathrm{~s}$ after termination of the odor pulse. Statistical analysis: two-way ANOVA with Bonferroni post hoc test, $* p<0.05$; $* * p<0.01$. $\boldsymbol{E}, \boldsymbol{F}$, Average velocity of flies that are $>3 \mathrm{~cm}$ away from the odor port is unaffected by knockdown of GABA receptors for 1:5 (E) 1:1 $(\boldsymbol{F})$ Eb odor pulses. Mean \pm SEM. $N=200-300$ flies.

LNs, which receive excitatory odor-induced inputs from multiple glomeruli and then inhibit OSN presynaptic terminals and PN postsynaptic dendrites (Stocker et al., 1990; Ng et al., 2002). Most individual LNs innervate a large number of glomeruli (Chou et al., 2010; Seki et al., 2010). OSN presynaptic activity could be modulated by the sustained activity of LNs (Wilson et al., 2004; Wilson and Laurent, 2005; Chou et al., 2010; Nagel et al., 2015), or a transient increase in LN activity upon a sharp decline in odor intensity (Nagel et al., 2015). A recent study has shown the presence of GABAergic LNs, which respond to odor offsets (Nagel and Wilson, 2016) and would be perfectly suited to mediate temporal contrast enhancement. It is also possible that slow kinetics of metabotropic $\mathrm{GABA}_{B}$ receptors mediate sustained inhibition after a rapid decline in odor intensity (Wilson and Laurent, 2005). Given the combined role of $\mathrm{GABA}_{A}$ and $\mathrm{GABA}_{B}$ receptors in temporal contrast enhancement, it is likely that a com- 


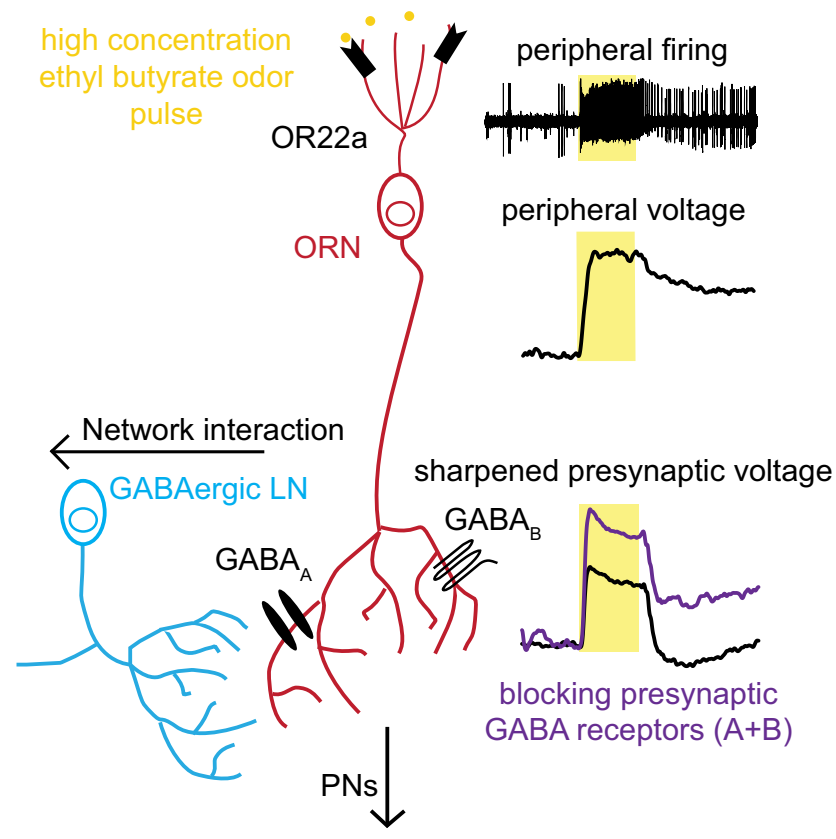

temporally contrast enhanced behavioral response

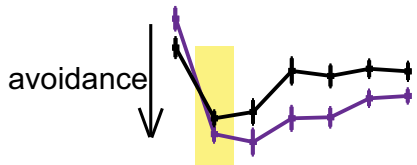

Figure 9. $\mathrm{GABA}_{\mathrm{A}}$ and $\mathrm{GABA}_{\mathrm{B}}$ receptors mediate presynaptic inhibition of OSNs to implement temporal contrast enhancement of sustained peripheral responses. A $1 \mathrm{~s}$ ethyl butyrate odor pulse (yellow boxes) of high concentration induces sustained peripheral neuronal activity in dendrites and cell bodies of OR22a-expressing OSNs. GABAergic LNs activate $\mathrm{GABA}_{A}$ and $G_{A B A}$ receptors, leading to temporally sharpened odor responses in presynaptic terminals. Presynaptic sharpening contributes in mediating temporal contrast enhancement improving the detection of termination of a high-intensity odor pulse.

bination of the intrinsic physiological properties of LNs and the kinetics of GABA receptor activation contribute to shaping the time course of presynaptic inhibition that underlies temporal contrast enhancement. Future studies are required to probe the role of this mechanism in actual plume-guided navigation.

\section{References}

Ache BW, Young JM (2005) Olfaction: diverse species, conserved principles. Neuron 48:417-430. CrossRef Medline

Anderson JS, Carandini M, Ferster D (2000) Orientation tuning of input conductance, excitation, and inhibition in cat primary visual cortex. J Neurophysiol 84:909-926. Medline

Asahina K, Louis M, Piccinotti S, Vosshall LB (2009) A circuit supporting concentration-invariant odor perception in Drosophila. $J$ Biol 8:9 CrossRef Medline

Buldyrev I, Taylor WR (2013) Inhibitory mechanisms that generate centre and surround properties in ON and OFF brisk-sustained ganglion cells in the rabbit retina. J Physiol 591:303-325. CrossRef Medline

Cao G, Platisa J, Pieribone VA, Raccuglia D, Kunst M, Nitabach MN (2013) Genetically targeted optical electrophysiology in intact neural circuits. Cell 154:904-913. CrossRef Medline
Celani A, Villermaux E, Vergassola M (2014) Odor landscapes in turbulent environments. Phys Rev X 4:041015. CrossRef

Chait M, Poeppel D, Simon JZ (2008) Auditory temporal edge detection in human auditory cortex. Brain Res 1213:78-90. CrossRef Medline

Chen TW, Wardill TJ, Sun Y, Pulver SR, Renninger SL, Baohan A, Schreiter ER, Kerr RA, Orger MB, Jayaraman V, Looger LL, Svoboda K, Kim DS (2013) Ultrasensitive fluorescent proteins for imaging neuronal activity. Nature 499:295-300. CrossRef Medline

Chou YH, Spletter ML, Yaksi E, Leong JC, Wilson RI, Luo L (2010) Diversity and wiring variability of olfactory local interneurons in the Drosophila antennal lobe. Nat Neurosci 13:439-449. CrossRef Medline

Clark DA, Fitzgerald JE, Ales JM, Gohl DM, Silies MA, Norcia AM, Clandinin TR (2014) Flies and humans share a motion estimation strategy that exploits natural scene statistics. Nat Neurosci 17: 296-303. CrossRef

Couto A, Alenius M, Dickson BJ (2005) Molecular, anatomical, and functional organization of the Drosophila olfactory system. Curr Biol 15:1535-1547. CrossRef Medline

Cury KM, Uchida N (2010) Robust odor coding via inhalationcoupled transient activity in the mammalian olfactory bulb. Neuron 68:570-585. CrossRef Medline

de Bruyne M, Foster K, Carlson JR (2001) Odor coding in the Drosophila antenna. Neuron 30:537-552. Medline

Delamater AR, Desouza A, Rivkin Y, Derman R (2014) Associative and temporal processes: a dual process approach. Behav Processes 101:38-48. CrossRef Medline

Dietzl G, Chen D, Schnorrer F, Su KC, Barinova Y, Fellner M, Gasser B, Kinsey K, Oppel S, Scheiblauer S, Couto A, Marra V, Keleman K, Dickson BJ (2007) A genome-wide transgenic RNAi library for conditional gene inactivation in Drosophila. Nature 448:151-156. CrossRef Medline

Fiala A, Spall T (2003) In vivo calcium imaging of brain activity in Drosophila by transgenic cameleon expression. Sci STKE 2003: PL6. CrossRef Medline

Fujiwara T, Kazawa T, Sakurai T, Fukushima R, Uchino K, Yamagata T, Namiki S, Haupt SS, Kanzaki R (2014) Odorant concentration differentiator for intermittent olfactory signals. J Neurosci 34: 16581-16593. CrossRef Medline

Gaudry Q, Nagel KI, Wilson RI (2012) Smelling on the fly: sensory cues and strategies for olfactory navigation in Drosophila. Curr Opin Neurobiol 22:216-222. CrossRef Medline

Hallem EA, Carlson JR (2006) Coding of odors by a receptor repertoire. Cell 125:143-160. CrossRef Medline

Hammer M, Menzel R (1995) Learning and memory in the honeybee. J Neurosci 15:1617-1630. Medline

Jin L, Han Z, Platisa J, Wooltorton JR, Cohen LB, Pieribone VA (2012) Single action potentials and subthreshold electrical events imaged in neurons with a fluorescent protein voltage probe. Neuron 75: 779-785. CrossRef Medline

Kaupp UB (2010) Olfactory signalling in vertebrates and insects: differences and commonalities. Nat Rev Neurosci 11:188-200. CrossRef Medline

Kuffler SW (1953) Discharge patterns and functional organization of mammalian retina. J Neurophysiol 16:37-68. Medline

Lei H, Riffell JA, Gage SL, Hildebrand JG (2009) Contrast enhancement of stimulus intermittency in a primary olfactory network and its behavioral significance. J Biol 8:21 CrossRef Medline

Liu X, Davis RL (2009) The GABAergic anterior paired lateral neuron suppresses and is suppressed by olfactory learning. Nat Neurosci 12:53-59. CrossRef Medline

Liu X, Krause WC, Davis RL (2007) GABAA receptor RDL inhibits Drosophila olfactory associative learning. Neuron 56:1090-1102. CrossRef Medline

Liu X, Buchanan ME, Han KA, Davis RL (2009) The GABA $A_{A}$ receptor RDL suppresses the conditioned stimulus pathway for olfactory learning. J Neurosci 29:1573-1579. CrossRef Medline 
Lledo PM, Saghatelyan A, Lemasson M (2004) Inhibitory interneurons in the olfactory bulb: from development to function. Neuroscientist 10:292-303. CrossRef Medline

Llinás R, Sugimori M, Silver RB (1992) Microdomains of high calcium concentration in a presynaptic terminal. Science 256:677-679. Medline

MacLeod K, Laurent G (1996) Distinct mechanisms for synchronization and temporal patterning of odor-encoding neural assemblies. Science 274:976-979. Medline

Manenti T, Pertoldi C, Moghadam NN, Schou MF, Kjærsgaard A, Cavicchi S, Loeschcke V (2015) Inbreeding affects locomotor activity in Drosophila melanogaster at different ages. Behav Genet 45:127-134. CrossRef Medline

Martelli C, Carlson JR, Emonet T (2013) Intensity invariant dynamics and odor-specific latencies in olfactory receptor neuron response. J Neurosci 33:6285-6297. CrossRef Medline

Matkovic T, Siebert M, Knoche E, Depner H, Mertel S, Owald D, Schmidt M, Thomas U, Sickmann A, Kamin D, Hell SW, Bürger J, Hollmann C, Mielke T, Wichmann C, Sigrist SJ (2013) The Bruchpilot cytomatrix determines the size of the readily releasable pool of synaptic vesicles. J Cell Biol 202:667-683. CrossRef Medline

McGann JP, Pírez N, Gainey MA, Muratore C, Elias AS, Wachowiak M (2005) Odorant representations are modulated by intra- but not interglomerular presynaptic inhibition of olfactory sensory neurons. Neuron 48:1039-1053. CrossRef

Mittmann W, Koch U, Häusser M (2005) Feed-forward inhibition shapes the spike output of cerebellar Purkinje cells. J Physiol 563:369-378. CrossRef Medline

Murmu MS, Stinnakre J, Martin JR (2010) Presynaptic Ca2+ stores contribute to odor-induced responses in Drosophila olfactory receptor neurons. J Exp Biol 213:4163-4173. CrossRef Medline

Murmu MS, Stinnakre J, Réal E, Martin JR (2011) Calcium-stores mediate adaptation in axon terminals of olfactory receptor neurons in Drosophila. BMC Neurosci 12:105. CrossRef Medline

Mylne KR, Mason PJ (1991) Concentration fluctuation measurements in a dispersing plume at a range of up to $1000 \mathrm{~m}$. Q J R Meteorol Soc 117:177-206. CrossRef

Nagel KI, Wilson RI (2011) Biophysical mechanisms underlying olfactory receptor neuron dynamics. Nat Neurosci 14:208-216. CrossRef Medline

Nagel KI, Wilson RI (2016) Mechanisms underlying population response dynamics in inhibitory interneurons of the Drosophila antennal lobe. J Neurosci 36:4325-4338. CrossRef

Nagel KI, Hong EJ, Wilson RI (2015) Synaptic and circuit mechanisms promoting broadband transmission of olfactory stimulus dynamics. Nat Neurosci 18:56-65. CrossRef Medline

Ng M, Roorda RD, Lima SQ, Zemelman BV, Morcillo P, Miesenböck G (2002) Transmission of olfactory information between three populations of neurons in the antennal lobe of the fly. Neuron 36:463-474. Medline

Ni JQ, Liu LP, Binari R, Hardy R, Shim HS, Cavallaro A, Booker M, Pfeiffer BD, Markstein M, Wang H, Villalta C, Laverty TR, Perkins LA, Perrimon N (2009) A Drosophila resource of transgenic RNAi lines for neurogenetics. Genetics 182:1089-1100. CrossRef Medline

Oheim M, Kirchhoff F, Stühmer W (2006) Calcium microdomains in regulated exocytosis. Cell Calcium 40:423-439. CrossRef Medline

Olsen SR, Wilson RI (2008) Lateral presynaptic inhibition mediates gain control in an olfactory circuit. Nature 452:956-960. CrossRef Medline

Pírez N, Wachowiak M (2008) In vivo modulation of sensory input to the olfactory bulb by tonic and activity-dependent presynaptic inhibition of receptor neurons. J Neurosci 28:6360-6371. CrossRef Medline

Poo C, Isaacson JS (2009) Odor representations in olfactory cortex: "sparse" coding, global inhibition, and oscillations. Neuron 62: 850-861. CrossRef Medline
Pouille F, Scanziani M (2001) Enforcement of temporal fidelity in pyramidal cells by somatic feed-forward inhibition. Science 293: 1159-1163. CrossRef Medline

Raccuglia D, Mueller U (2013) Focal uncaging of GABA reveals a temporally defined role for GABAergic inhibition during appetitive associative olfactory conditioning in honeybees. Learn Mem 20: 410-416. CrossRef Medline

Raccuglia D, Mueller U (2014) Temporal integration of cholinergic and GABAergic inputs in isolated insect mushroom body neurons exposes pairing-specific signal processing. J Neurosci 34:1608616092. CrossRef Medline

Root CM, Masuyama K, Green DS, Enell LE, Nässel DR, Lee CH, Wang JW (2008) A presynaptic gain control mechanism fine-tunes olfactory behavior. Neuron 59:311-321. CrossRef Medline

Sachse S, Galizia CG (2002) Role of inhibition for temporal and spatial odor representation in olfactory output neurons: a calcium imaging study. J Neurophysiol 87:1106-1117. Medline

Seki Y, Rybak J, Wicher D, Sachse S, Hansson BS (2010) Physiological and morphological characterization of local interneurons in the Drosophila antennal lobe. J Neurophysiol 104:1007-1019. CrossRef Medline

Semmelhack JL, Wang JW (2009) Select Drosophila glomeruli mediate innate olfactory attraction and aversion. Nature 459:218223. CrossRef Medline

Shusterman R, Smear MC, Koulakov AA, Rinberg D (2011) Precise olfactory responses tile the sniff cycle. Nat Neurosci 14:10391044. CrossRef Medline

Silbering AF, Galizia CG (2007) Processing of odor mixtures in the Drosophila antennal lobe reveals both global inhibition and glomerulus-specific interactions. J Neurosci 27:11966-11977. CrossRef Medline

Stocker RF, Lienhard MC, Borst A, Fischbach KF (1990) Neuronal architecture of the antennal lobe in Drosophila melanogaster. Cell Tissue Res 262:9-34. Medline

Stopfer M, Bhagavan S, Smith BH, Laurent G (1997) Impaired odour discrimination on desynchronization of odour-encoding neural assemblies. Nature 390:70-74. CrossRef Medline

Tully T, Quinn WG (1985) Classical conditioning and retention in normal and mutant Drosophila melanogaster. J Comp Physiol A 157:263-277. Medline

Urban NN (2002) Lateral inhibition in the olfactory bulb and in olfaction. Physiol Behav 77:607-612. Medline

van Breugel F, Dickinson MH (2014) Plume-tracking behavior of flying Drosophila emerges from a set of distinct sensory-motor reflexes. Curr Biol 24:274-286. CrossRef Medline

Vosshall LB, Amrein H, Morozov PS, Rzhetsky A, Axel R (1999) A spatial map of olfactory receptor expression in the Drosophila antenna. Cell 96:725-736. Medline

Vosshall LB, Wong AM, Axel R (2000) An olfactory sensory map in the fly brain. Cell 102:147-159. Medline

Wallace DG, Gorny B, Whishaw IQ (2002) Rats can track odors, other rats, and themselves: implications for the study of spatial behavior. Behav Brain Res 131:185-192. Medline

Wehr M, Zador AM (2003) Balanced inhibition underlies tuning and sharpens spike timing in auditory cortex. Nature 426:442-446. CrossRef Medline

Wilson RI, Laurent G (2005) Role of GABAergic inhibition in shaping odor-evoked spatiotemporal patterns in the Drosophila antennal lobe. J Neurosci 25:9069-9079. CrossRef Medline

Wilson RI, Turner GC, Laurent G (2004) Transformation of olfactory representations in the Drosophila antennal lobe. Science 303:366370. CrossRef Medline

Zaninovich OA, Kim SM, Root CR, Green DS, Ko KI, Wang JW (2013) A single-fly assay for foraging behavior in Drosophila. J Vis Exp e50801. 